\title{
Governmental Stakeholders Impact on Construction Projects in Oman
}

\author{
Osama Salim Al Adawi \\ Said Salim Al Hina \\ Hussin A. M. Yahia \\ Ram Kishore Manchiryal
}

\author{
Middle East College \\ Middle East College \\ Middle East College \\ MIDDLE EAST COLLEGE
}

\begin{abstract}
Organizations and companies who are working on construction sector within Oman are suffering from running into the bureaucracy process which established within the governmental stakeholders to obtain approvals and permissions like NOCs (No Objection Certificates). The objectives of this Research are to identify the impact of governmental stakeholders on delaying projects completion as a result of lengthy process of granting NOCs and subsequently design a platform which will guarantee a flat process for approaching information and issuing approvals. Three research methodologies have been implemented in this study. The first one was a quantitative where questionnaire distributed to selective personnel who are working in construction project environment and representing different local companies. The second one was a qualitative method where interviews with project managers, senior engineers and leaders in the construction field has been conducted to understand the impact caused by long approval process in their projects' lifecycle. The third one was an expert system where an online platform is developed and sought to expedite the approvals process from governmental stakeholders and accordingly evaluate the compatibility and reliability of the system through selective personnel from the construction sector. The expected outcomes of this study are to achieve a solution with an aim at speeding up issuing NOCs and approvals obtainment as well as diminishing the needless processes practiced by governmental stakeholders in the built environment within Oman.
\end{abstract}

\section{Introduction}

Governmental Stakeholders are the authorities and ministries that belong to the government and several approvals and NOCs are required to be obtained from them by the construction companies in order to commence and complete any project. The governmental stakeholders are one of the crucial parts of any construction project in Oman that contributes in projects' success. On top of that, they can also delay the completion of projects as approval process might take long time which affect the construction schedule as well as the cost. based on ISFU-Oman report, 77 projects in Oman were delayed or hindered due to lack of governance and stakeholders' integration and slow approval process (ISFU 2017).

As a mean to improve the approval and NOCs granting processes established within the governmental stakeholders, and to minimize the time wasted in issuing approvals, this study has been conducted. The primary objectives of this research are as follows:

1. To understand the impact of lengthy approval process on construction projects' time and cost,

2. Accordingly develop an Expert System which shall aid companies within construction field to improve approvals process.

Moreover, the specific objectives of the study are established as followings:

1. Identify the governmental stakeholders involved within the construction projects of Marafi, 


\section{Journal of Student Research}

Fourth Middle East College Student Research Conference, Muscat, Sultanate of Oman

INSHA, Salalah Port and Oman Dry Dock companies as well as Contractors' stakeholders like Khimji Ramdas Construction and Ozkar Construction.

2. Examine the main reasons that delaying the approvals and NOCs processes.

3. Design an Expert System to minimize the time spent in issuing NOCs and approvals by the governmental stakeholders.

This Expert System is an online computerized platform where construction companies can apply for NOCs and approval requests through this platform and grant the NOCs quickly. This will considerably slash the time and cost of the construction projects. In addition, the study aims to evaluate the compatibility of the developed platform within the stakeholder management system of the government.

This study includes Four main Sections. In Section 1, literatures related to the Research area will be reviewed to enrich the study. Section 2 will discuss the Research methodologies that pursued for this study while in Section 3, the Research's results will be presented and critically discussed. Then, all Research's results and the required further works will be concluded in Section 4.

The primary sources used for this Research were meeting and interviewing personnel from the above-mentioned Companies. Also, distributing questionnaire to selected personnel who are working in the construction projects in Oman. The secondary sources used were journals, books, magazines, conference proceedings, reports, websites and newspapers.

Google Forms was used as the main platform for developing the questionnaire. The main distribution channel used is through social media app (WhatsApp) and official emails of the concerned personnel. Most of the respondents that were involved in filling the questionnaire are project managers from the construction industry in Oman.

\section{Literatures Review}

Since the selected research area is focusing on determining the impact of lengthy approval process of issuing NOCs and developing an online platform for expediting the approval and NOCs processes from the governmental stakeholders, there is a difficulty to find related studies with the same objectives and outcomes. There are limited resources to be utilized for the literatures review. However, different literatures have been reviewed and summarized in the following paragraphs.

Companies who are working on construction industry within Oman suffered from experiencing the bureaucracy process which are established within government stakeholders (external stakeholders) to issue approvals and permissions (Cotton and Mahroos-Alsaiari 2014). Due to the lengthy approval process, external stakeholders can accelerate, or delay construction works to a further extent and consequently will affect the construction schedule and the estimated cost of the project (Chan and Oppong 2017).

One of the effective solutions to overcome the impact caused by external stakeholders is to engage them properly from the early stages of any project and shall contribute approximately 44 per cent of total involvement in defining the pre-project planning stages (Fageha and Aibinu 2016). As a result, this will impact on their believes since the development procedure and decision making of the project is fair and thus accelerate future approvals required by them. Sina Safi Nia, 2017.

In a personal letter, Eng. Ahmed Abdelhamid whose working as a Construction Manager for Consolidated Contractors Company - Oman Branch explained that although the engagement of stakeholders from early stages is helping in accelerating the approvals processes, still companies in construction industry are confronting challenges in getting the approvals from governmental stakeholders in short time. The process is taking several months (sometimes 5-6 months) where committees must be established and review the requirements in order to issue an approval. This is 


\section{Journal of Student Research}

Fourth Middle East College Student Research Conference, Muscat, Sultanate of Oman

consequently delay project's completion and lifting-up the cost which will be later claimed by the companies and accordingly affect the government budget. Therefore, an online solution must be introduced to expedite the process and optimize projects' cost and time. (Abdelhamid 2019). Also, insufficient documentation and requirements cause a delay in the approval process (Botchway et al. 2014).

The swift development of information and communication technologies (ICTs) are unlocking new opportunities for growth different countries around the world (Jaiswal 2018). Furthermore, and toward improving the governments bureaucracy processes and to reduce the costs of using traditional electronic governments, a model proposed to improve electronic government services. The results from using this model revealed that the adoption of the model provided an effective government services to the stakeholders of developing countries. Moreover, the proposed model promotes a smooth integration of government services and thus cuts the time of overall projects which revealed a considerable improvement in the performance (Joshi et al. 2017).

(Ali et al. 2018), proposed a platform to aid the government in overcoming the challenges which are confronting the data accessing and approval process. The proposed platform meant to establish a central data pool of shared information, resources and infrastructure which will expediate the process of approval and granting NOCs. The platform demonstrated a success model for an integrated platform where all stakeholders can apply and access easily. Furthermore, it is essential to develop an Expert System (online platform) to solve the issue of approval process as it has been demonstrated to be an effective solution in many researches. (Ladin et al. 2019), found that the reliability and effectiveness of an Expert System is very high and can be used as dynamic tool to be improved/updated from time to time.

In addition, when authorities can upload or share reports/drawings/plans online, the review process and comments will significantly be quicker than do it manually. For example, Permit request applications can be directed to other authorities' reviewers which will allow parallel reviewing performance. This promotes the integration among companies and authorities as users can submit applications via a single access point (One-Stop-Shop) without visiting multiple stakeholders separately, consequently this is reducing the companies' compliance costs and authorities' administrative costs (Molfetas and Wille 2018). Too, it has proven that One-Stop-Shop solution can bridge the lack of knowledge among different parties related to a certain project (Costanzo et al. 2017). Also, it can reduce the time and cost spent in visiting multiple authorities (Meacham et al. 2019). Besides, (Akinyemi et al. 2018) revealed in their study that leveraging information integration technologies in construction sector can be beneficial as reveals that by adopting online web technologies can make substantial savings in time when compared to traditional information management approach. The process time using electronic permitting system for construction projects can be slashed up to 25 days (Shahi 2018). As well, government time and cost will be saved, easier tracking for the approvals request, requirements are accessible anytime, engineering reviews for the submittals can be accessed and processed anywhere and errors are reduced (Smyrichinsky and Kramer 2018).

\section{Research Methodologies}

One of the methodologies used to achieve this Research's objectives is quantitative through distributing questionnaire to selective samples. The Research conducted on selective Companies which are working and running construction projects in Oman. These Companies are Marafi, INSHA, Salalah Port, Oman Dry Dock, Khimji Ramdas Construction and Ozkar Construction. The Research samples has been calculated using the following formula:

\section{a. Sample Size Calculation:}

Sample Size $=($ Distribution of 50\%) $/(($ Margin of Error (5\%) / Confidence Level Score (95\%) $)$ 
Squared)

\title{
b. Finite Population Correction:
}

\author{
True Sample $=($ Sample Size X Population $) /($ Sample Size + Population -1$)$
}

The Population has been determined to be 85 numbers which include Top Management, General Managers, Project Managers, Senior Engineers who are working in the selected Companies. Therefore, using the above formula, the true required sample is calculated to be 70 samples.

The questionnaire has been prepared using Google Form platform with a total of 39 questions. The questions divided into general information and specific information where the Research is focused. The questionnaire's questions designed to understand the impacts caused by the lengthy approval process established within the governmental stakeholders. Also, to know the acceptance level and the satisfaction of introducing an online platform where all companies in construction industry can apply for approvals and get the NOCs quickly. The questions have been derived from a similar survey which was conducted by World Bank Group in 2018 about the leveraging Technology to Support Construction Regulation and Permitting Reform.

The questionnaire has been distributed to the selected Companies personnel through different communication channels like social media app (WhatsApp). Accordingly, the required true samples have been acquired and the results exported from Google Forms platform to SPSS software so it can be analyzed later.

Before inserting the data in SPSS, the results have been filtered and decoded in MS Excel and then exported to SPSS. The data has been analyzed based on the frequencies of the different information which gathered from the Respondents. Too, crosstabs were leveraged to compare different responses where applicable especially when comparing general questions with the specific questions.

The general questions include ages, work experience, gender, and nationality of the Respondents. Where, specific questions asked about the type of project, the interference level with governmental stakeholders, time required to obtain NOCs from stakeholders, number of governmental stakeholders required to be approached for single NOC and other different questions. These questions designed to get the right responses in order to achieve the Research objectives. In addition, the statistics reliability value was identified by finding Cronbach's Alpha using SPSS feature.

Furthermore, the results derived from the responses divided into 3 main parts which are the impacts and reasons of long approval process, an online platform solution (Expert System) and the acceptance of this platform by the Respondents. In part 1, the reasons and impacts of the lengthy approval process were identified based on a percentage wise and frequencies wise which are resulting from the responses and then presented and analyzed in a shape of charts and tables. The results in part 1 are meant to drive the decision of whether to implement an Expert System not. In part 2 , the questions and responses which related to the online platform were analyzed and three factors were identified which were behind the main reasons to adopt the online platform. These factors are the location, time and services. In Part 3, the questions' responses which measure the level of Respondents' acceptance for introducing a platform were analyzed to test the water and confirm if it would be beneficial for Respondents' projects to expedite their projects completion timeframe.

Finally, the results were analyzed and critically discussed by deliberating the responses and benchmarking with similar previous studies in the same research area. These results will be linked and validated with the Qualitative method in the Conclusion Section. 
In this Research, in addition to Quantitative Methodology, a Qualitative Methodology has been used. Three interview questions have been prepared and interviews conducted for 10 selected personnel from the construction industry. The interviews conducted through different methods like face-to-face and mobile phone. The selected personnel for the interviews are particularly from the Companies selected for the Quantitative method. Those personnel were selected due to their considerable experience in the construction sector and close liaisons with governmental stakeholders.

The 10 interviewees responses were written, and transcripts have been coded and analyzed accordingly by arranging them using cohesive themes. The interviews records and transcripts were documented. Then, the responses reviewed and explored. After that, initial codes which linked to the Research area were created from these responses. Next, the codes were revised and combined into different themes as applicable. Finally, these themes were presented in a unified manner and the results validated with the Quantitative method results.

The interview questions were focused on three aspects. These are the impacts of governmental stakeholders on cost and time, challenges that encountering when issuing NOCs and the possible solution for improving the process. After revising the responses, three main themes derived from the transcripts. These themes are Approval Process Time, Requirements and One- Stop-Shop Platform. The themes created to link all the findings from the Responses and represent them in an understandable format so they can be analyzed and validated with the Quantitative methodology results. Finally, the results analyzed using different illustrative charts and tables and compared with similar studies' findings.

Expert System methodology has been done through various steps which include data collection from journals, websites and field experts. The information acquisition process is very important to deliver the optimal strategy to achieve the objectives of this Research. Next, the collected information was coded using different programming languages to develop the online platform. The flow chart shown in Figure 1 illustrates the process of developing the platform.

\section{Expert System (Online Platform) - Development Process}
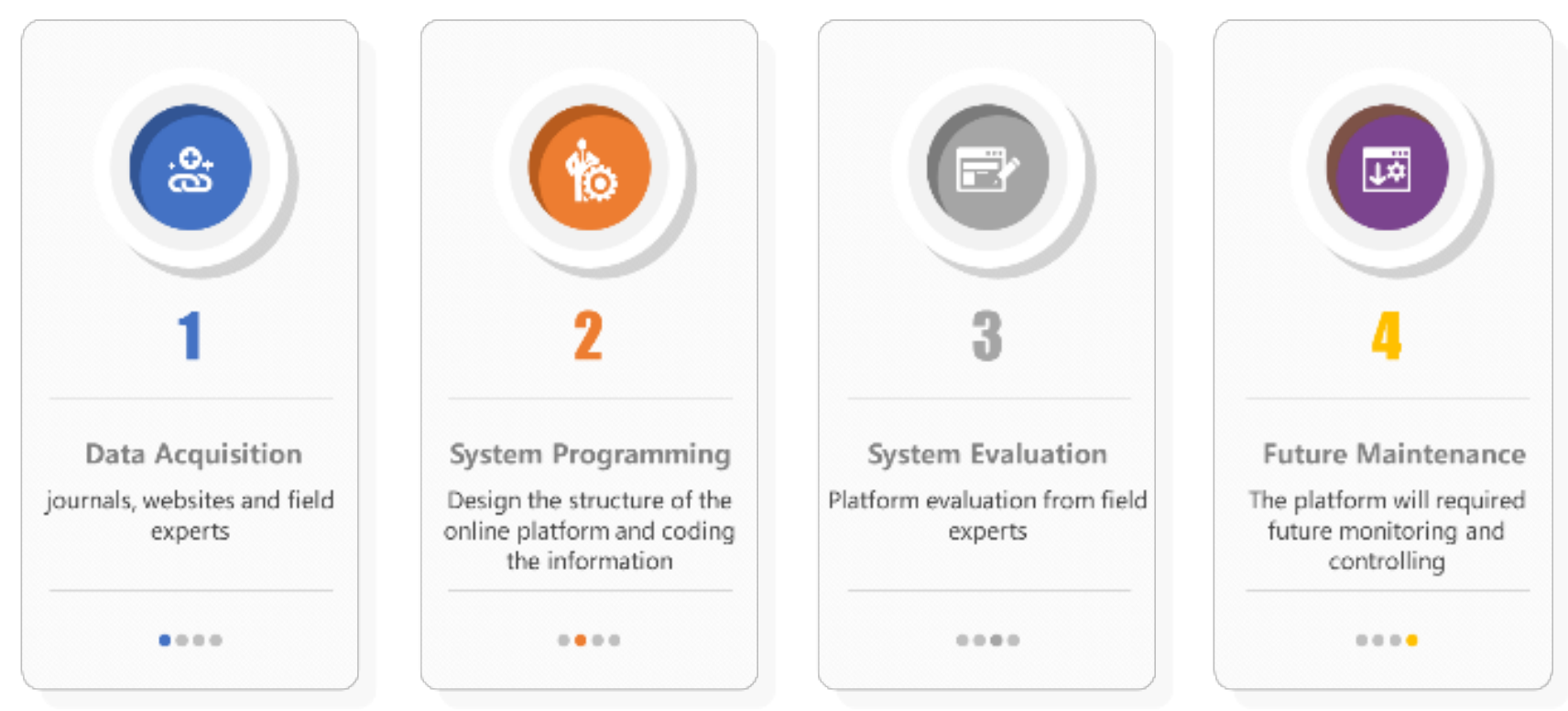

Figure 1. Development Steps of the Expert System Platform

The development process went through 4 steps as shown in the above Figure. After gathering the 


\section{Journal of Student Research}

Fourth Middle East College Student Research Conference, Muscat, Sultanate of Oman

data and programmed into platform. The system evaluated by different representatives from the construction field. Then the platform shall be maintained in the future by a sponsor.

Programming language Php, Java, Bootstrap and MySQL were used for this study to develop an Expert System - online platform. The pertinent information attained from different sources was coded as a data base for the platform. For the development of the platform, the followings steps were pursued:

Step 1- Creating Platform Interface: The interface of the platform has been designed to be a user friendly and, in both languages, (Arabic and English). The interface includes the main buttons and important links where the users can use directly for NOCs applications. Also, a search bar was included so the users can approach to the required subject easily. Figure 2 shows a capture of the platform interface.

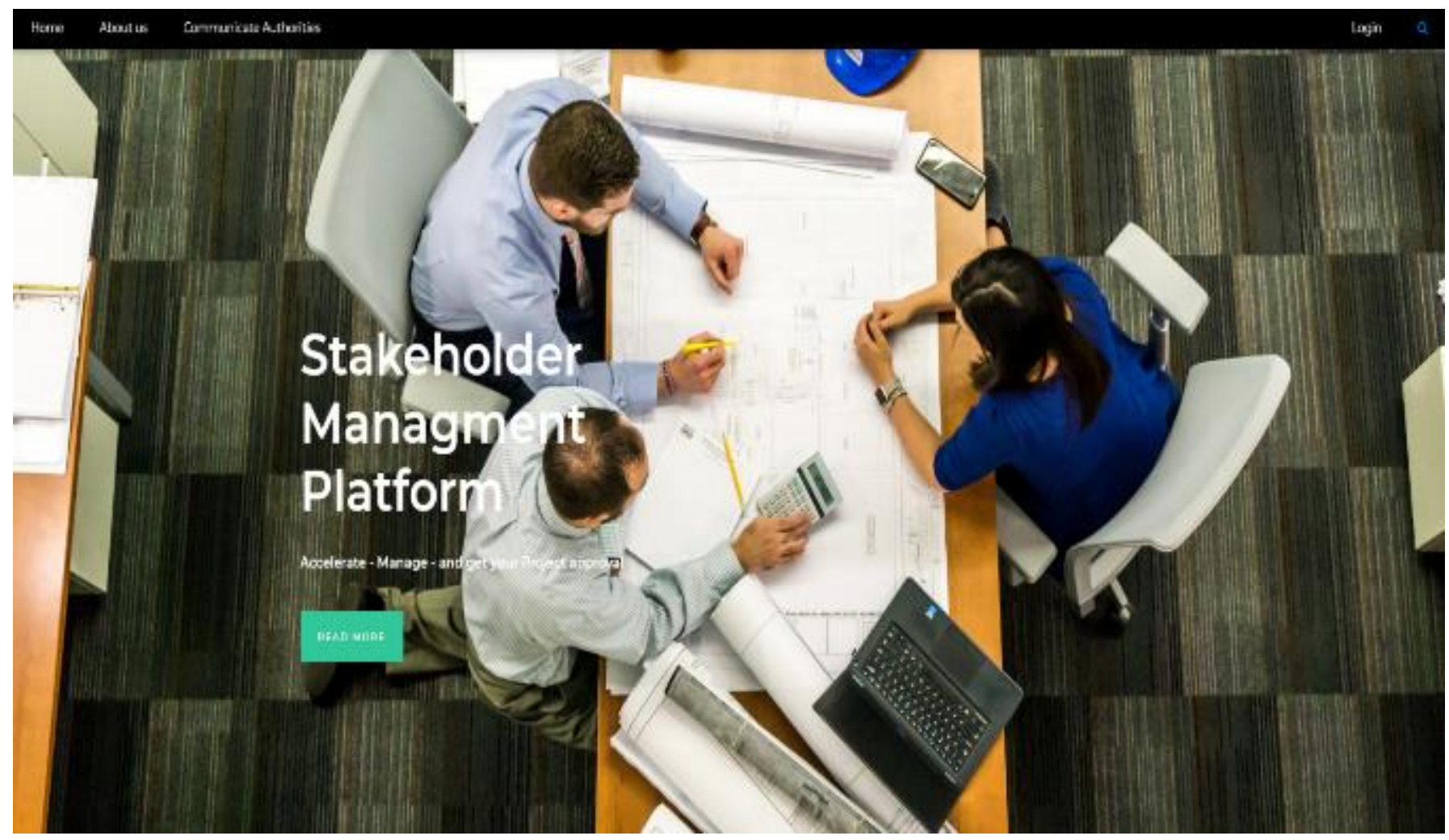

Figure 2. Online Platform Interface

The platform designed in a way that support the dynamic interaction between users. So, a company representative can login to the system and request for approval and the governmental stakeholder can review the request and action accordingly. It will work as One-Stop-Shop where all companies in construction industry within Oman can apply/request for approvals/NOCs. The approvals can be granted through the system and in a short time.

Step 2- Inserting the Information: The collected information about the governmental stakeholders like the profiles, projects, contact details and required information to be uploaded for NOC requests have been inserted to the Platform. In addition, the requirements of these stakeholders have been inserted so the users can navigate them and upload the correct documents.

Step 3- Platform Functions and Features Design Different: functions and features have been designed for the platform like users can have their own user name, stakeholders and their requirements can be reviewed. Also, requests can be tracked. Figures 3-6 explains and captures the functions developed before running the system. 


\section{Journal of Student Research}

Fourth Middle East College Student Research Conference, Muscat, Sultanate of Oman

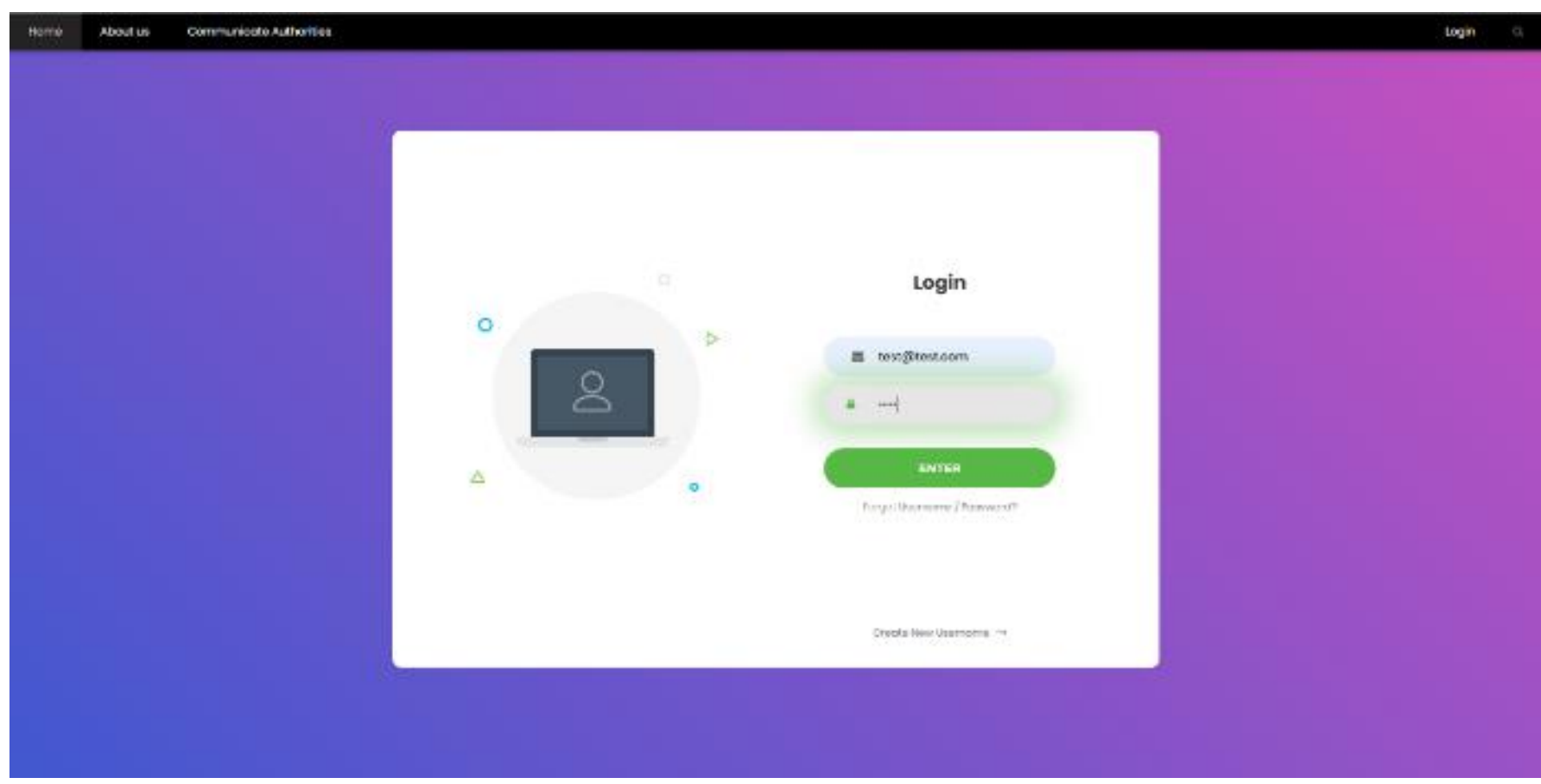

Figure 3. Platform Login Tab

The capture above shows the login tab where each construction company and governmental stakeholders will have a designated username and password.

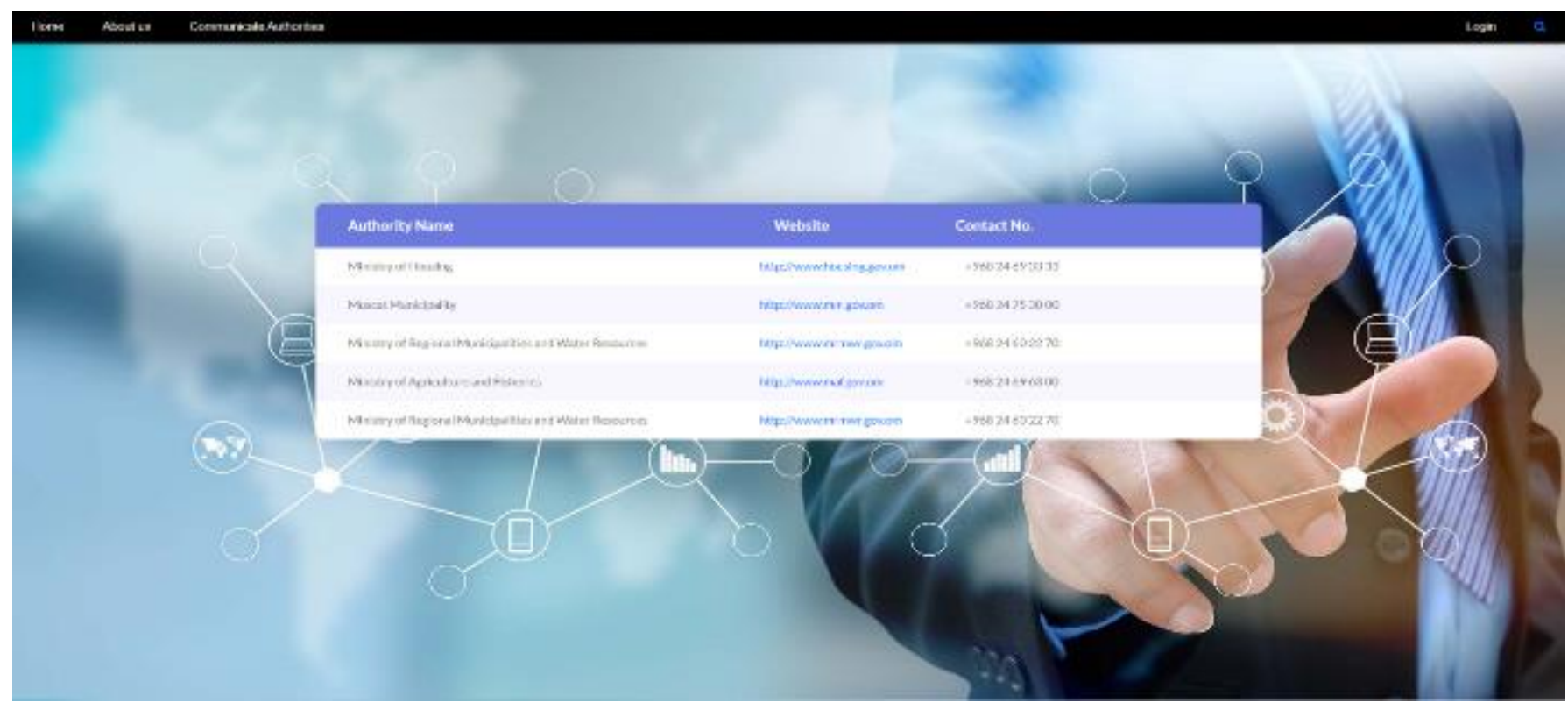

Figure 4. Contacts Details for Governmental Stakeholders

As shown in captured above, the platform includes a list of the important governmental stakeholders with their contact details so the companies' representative can communicate directly if there is an issue occurred while requesting an approval. 


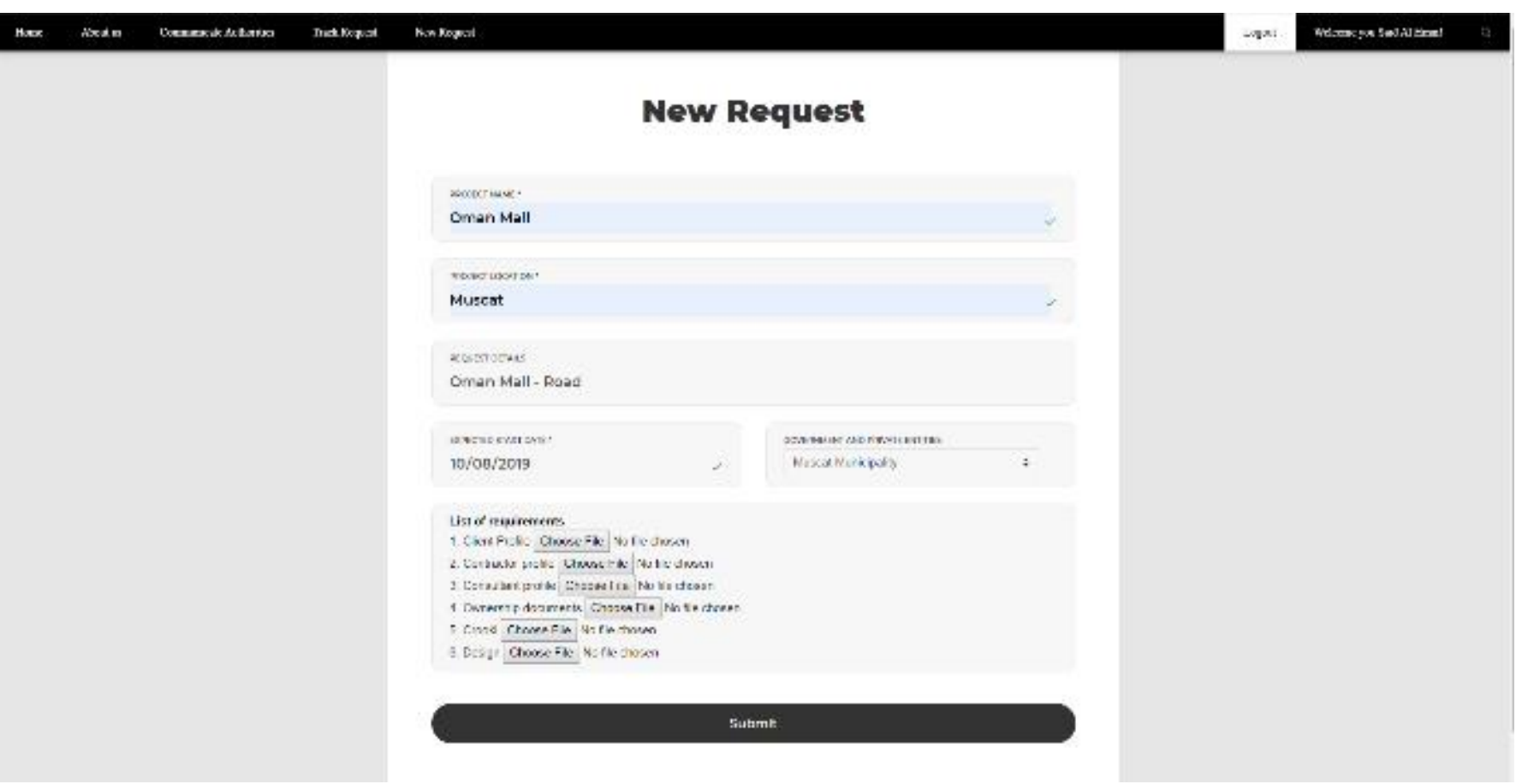

Figure 5. New Request through the Platform

The capture above shows that the user already logged in and new request window is appeared where the user can apply for a new approval request. The user can select the project location and then select the authority which required for the approval. List of requirements will be listed automatically where user can upload required documents, drawings and finally submit them.

\begin{tabular}{|c|c|c|c|}
\hline Nronsection number & Gowirimant Excites & stacus & Notss \\
\hline IA & Mutechardenty & nrapar & \\
\hline 1.) & shov now $x=d: x$ & hroive & \\
\hline
\end{tabular}

Figure 6. Request Tracking Function

Tracking numbers are generated automatically for all requests. Above capture shows the tracking requests window where user can view his request status and check if remarks are raised by the governmental stakeholders.

The application process through the platform is shown in flow-chart below: 


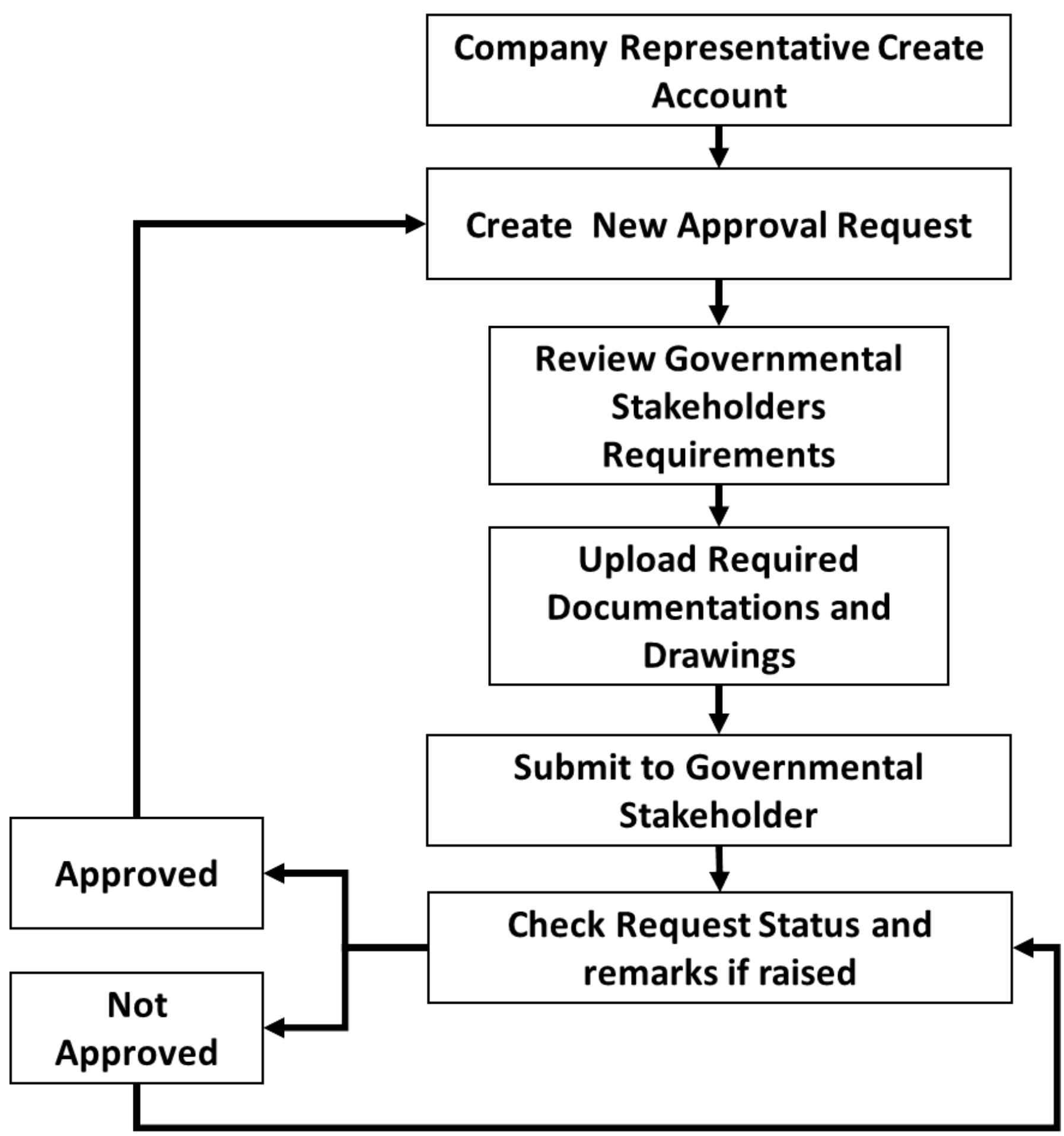

Figure 7. Platform Application Process Flow-Chart

To explain the above chart, all governmental stakeholders should have username in the platform. Then, the company's representative can create new username and apply for a new approval request. The stakeholder representative can review the request and then approve or reject the request with notes (within 10 days). The company representative can review the request status, if approved or not. If approved he can proceed with new request if required, if not approved, he should check the notes and accordingly contact the concerned authority through the platform.

Step 4- Run A Pilot: A server domain has been allocated to run a pilot for the platform. The platform has been introduced to different personnel from the selected Companies for this Research. 
This is to test and evaluate the acceptance level of the platform. The acceptance level has been measured thru the Quantitative methodology. Also, the pilot operated to ensure there is no error when using the system.

\section{Results and Critical Discussion}

\section{Quantitative Methodology Results-General Analysis}

Different managerial levels personnel with wide experience have been responded to the questionnaire. Table 1 is listing the respondents' positions with their experience:

\begin{tabular}{|c|c|c|c|c|c|c|}
\hline \multirow{2}{*}{\multicolumn{2}{|c|}{$\begin{array}{l}\text { Position/Experience of } \\
\text { Respondents }\end{array}$}} & \multicolumn{5}{|c|}{ Respondents' Position } \\
\hline & & \multirow{2}{*}{\begin{tabular}{|l|} 
Top \\
management \\
0 \\
\end{tabular}} & \multirow{2}{*}{\begin{tabular}{|l|}
$\begin{array}{l}\text { Project } \\
\text { Manager }\end{array}$ \\
0 \\
\end{tabular}} & \multirow{2}{*}{\begin{tabular}{|l}
$\begin{array}{c}\text { General } \\
\text { Manager }\end{array}$ \\
0 \\
\end{tabular}} & \multirow{2}{*}{$\begin{array}{l}\text { Sr. Engineer } \\
6 \\
\end{array}$} & \multirow{2}{*}{$\begin{array}{l}\text { Project } \\
\text { Engineer } \\
6 \\
\end{array}$} \\
\hline Years of & 0 -5Years & & & & & \\
\hline Experience & 6-11Years & 1 & 8 & 0 & 14 & 0 \\
\hline & 12-17Years & 3 & 20 & 2 & 1 & 1 \\
\hline & 18-23Years & 2 & 3 & 1 & 0 & 0 \\
\hline & $>23$ Years & 1 & 0 & 1 & 0 & 0 \\
\hline \multicolumn{2}{|c|}{ Total } & 7 & 31 & 4 & 21 & 7 \\
\hline \multicolumn{2}{|c|}{ Grand Total } & \multicolumn{5}{|c|}{70 Respondents } \\
\hline
\end{tabular}

Table 1. Research Respondents' Positions and Experience

Most Respondents are with Omani nationality which counted to be $82 \%$ of the total Respondents. The majority are working in consultancy and construction companies. Table 2 shows a comparison between the Nationalities and Companies type of the Respondents'.

\begin{tabular}{|c|c|c|c|c|c|}
\hline \multicolumn{2}{|c|}{ Company Type / Nationality } & \multicolumn{3}{|c|}{ Company Type } & \multirow[t]{2}{*}{ Total } \\
\hline & & \begin{tabular}{|l|} 
Engineering, \\
Consultant
\end{tabular} & \begin{tabular}{|c|} 
Contracting, \\
Construction
\end{tabular} & Client & \\
\hline \multirow[t]{2}{*}{ Nationality } & Omani & 31 & 13 & 14 & 58 \\
\hline & Non-Omani & 5 & 7 & 0 & 12 \\
\hline \multicolumn{2}{|c|}{ Total } & 36 & 20 & 14 & 70 \\
\hline
\end{tabular}

Table 2. Respondents' Nationality and Companies Type

High percentage of Omanization in the top positions of construction industry in Oman can be recognized. This should facilitate the communication among stakeholders within the industry.

Furthermore, those Respondents are running different types of projects and mostly Infrastructure Projects. Figure 8 shows the projects' types as answered by the Respondents. 


\section{What is the type of projects you are handling with the governmental stakeholders?}

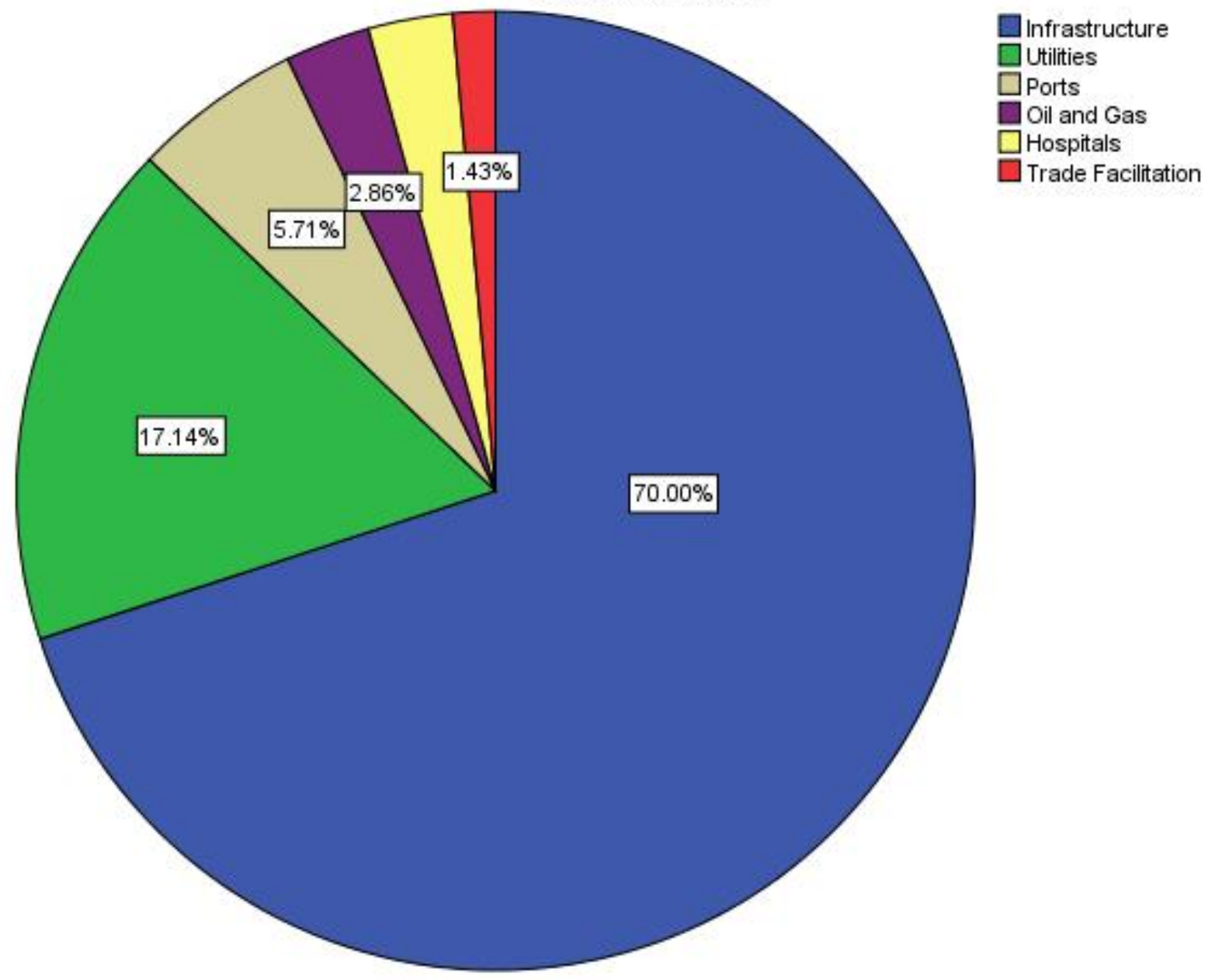

Figure 8. Respondents Projects' Types

The chart above reveals that most of the projects covered in this Research are Infrastructure Projects where multiple governmental stakeholders are involved. Respondents involved in the questionnaire might liaise/interfere with governmental stakeholders or not within their projects. Therefore, to ensure realistic responds from the Respondents, a question concerning whether the respondent is interfering with governmental stakeholders or not has been asked in the questionnaire. The results revealed that $97 \%$ of the Respondents answered "Yes" for this question as shown in Figure 9 below. The 3\% might work in a department where communication with governmental stakeholders are not required. 


\section{Journal of Student Research}

Fourth Middle East College Student Research Conference, Muscat, Sultanate of Oman

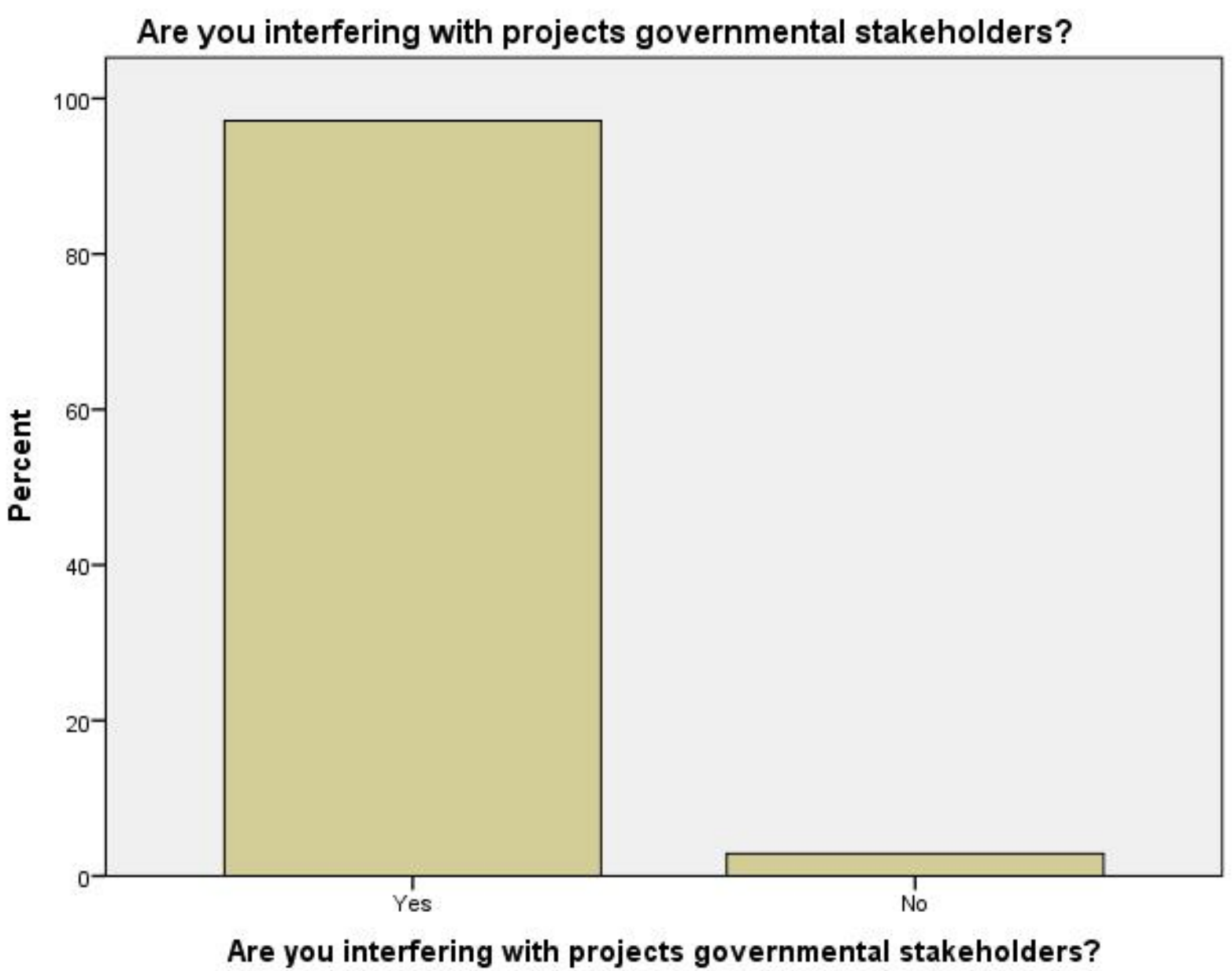

Figure 9. Respondents' Answers for Governmental Stakeholders Interfering Question

High percentage of those Respondents have a high level of interaction with the governmental stakeholders which would give reasonable answers. Figure 10 shows that 40 Respondents have a high level of interaction with governmental stakeholders where 27 Respondents have a medium level. Respondents' with low level are very minimal. 


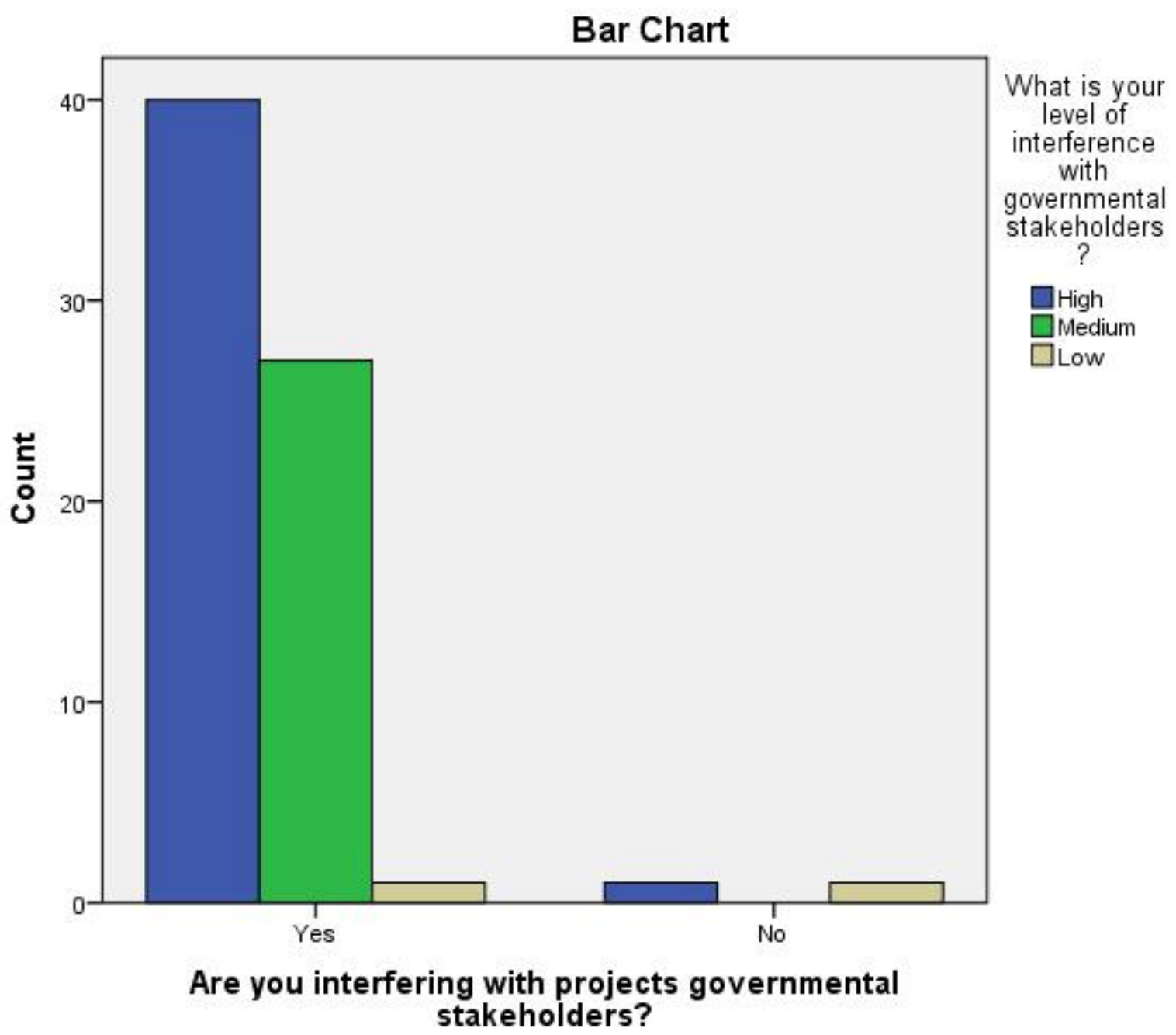

Figure 10. Interaction Level with Governmental Stakeholders Answers

\section{Quantitative Methodology Results - Impacts and Reasons of Lengthy Approval Process}

Based on the questionnaire's results, it was found that several reasons affected the duration of granting approvals and NOCs from the governmental stakeholders. Firstly, process of granting NOCs is itself lengthy within the governmental stakeholders' system which requires mostly 2-3 weeks to grant a single NOC as demonstrated in Figure 11. 


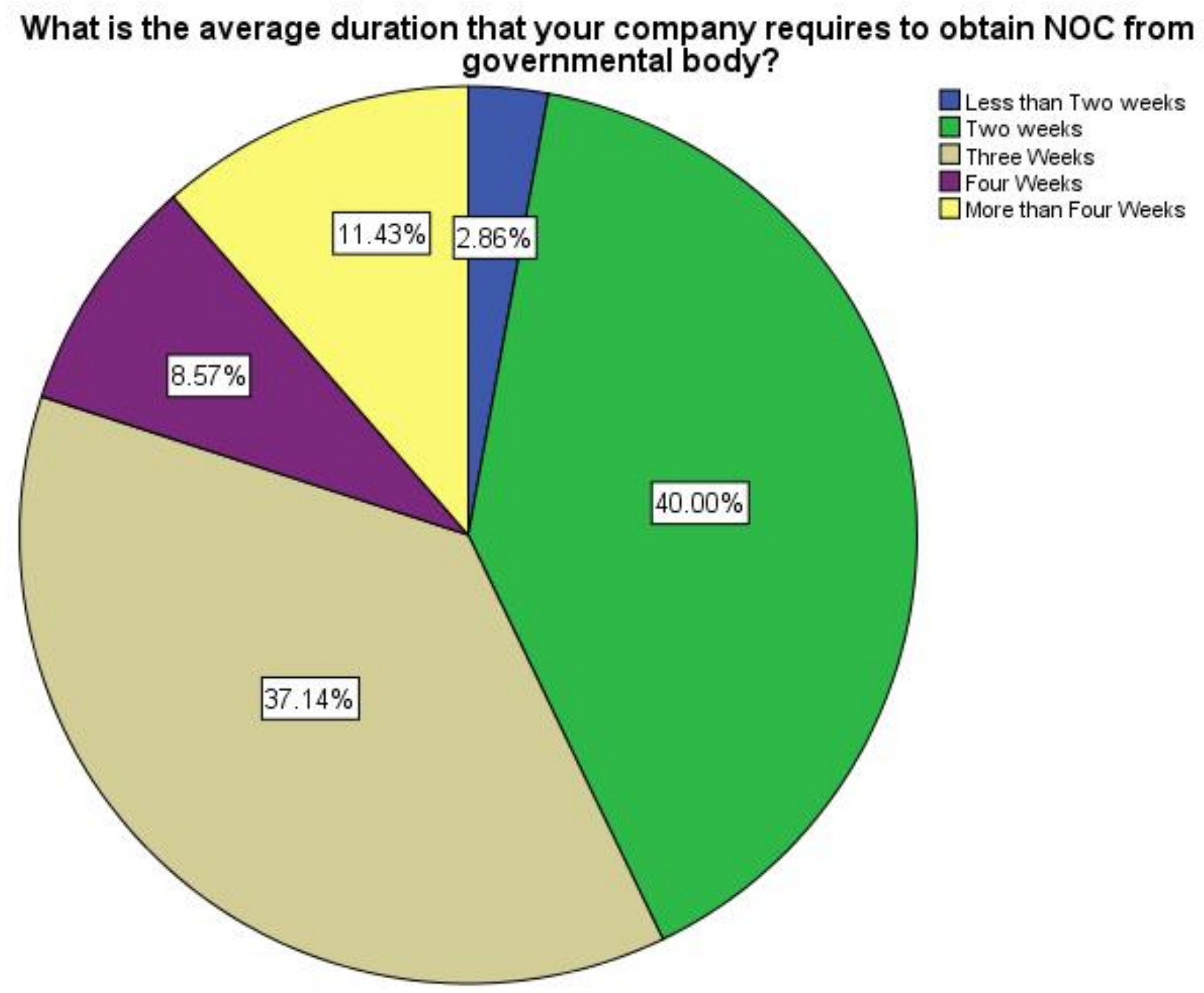

Figure 11. The Average Duration for Obtaining NOC

The statistics illustrated in the above pie chart give an indication to the necessity of accelerating the process of granting NOCs. Because the average duration for granting a single NOC according to the Respondents' is $2-3$ weeks. Also, $11.4 \%$ of Respondents take more than 4 weeks to issue NOC. One of the reasons which led to this such delay is the internal approval process that established within the governmental stakeholder system is complicated as confirmed by 42 Respondents which is demonstrated in Figure 12. In addition, the selected Companies must obtain approvals from several governmental stakeholders. The average is 5 governmental stakeholders to be approached for getting an approval for a single project as demonstrated in Figure 13. 


\section{Journal of Student Research}

Fourth Middle East College Student Research Conference, Muscat, Sultanate of Oman

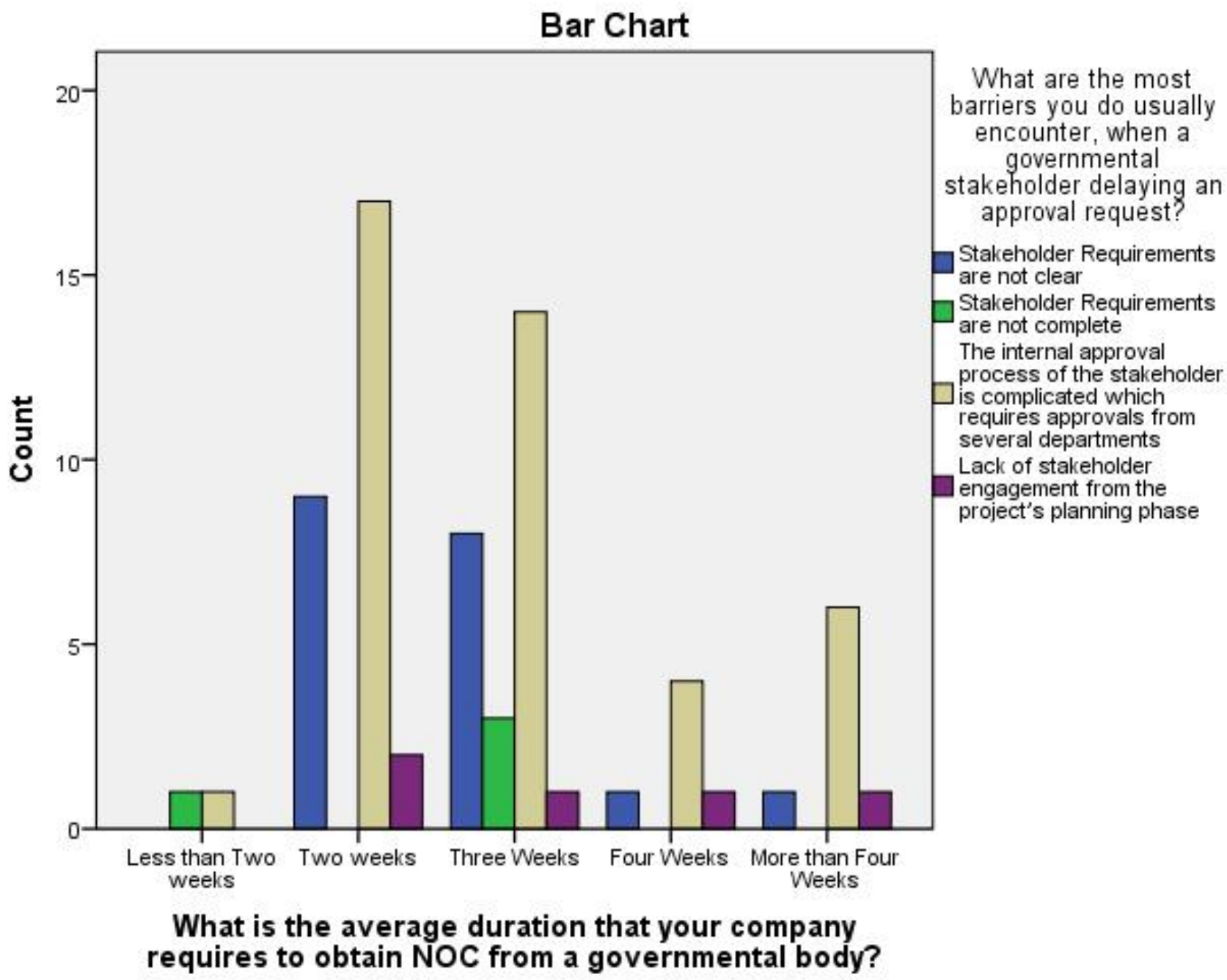

Figure 12. Average Duration for Obtaining NOC from A Governmental Stakeholder 


\section{Journal of Student Research}

\section{How many governmental stakeholders you do usually approach to obtain approvals/NOCs for a single project?}

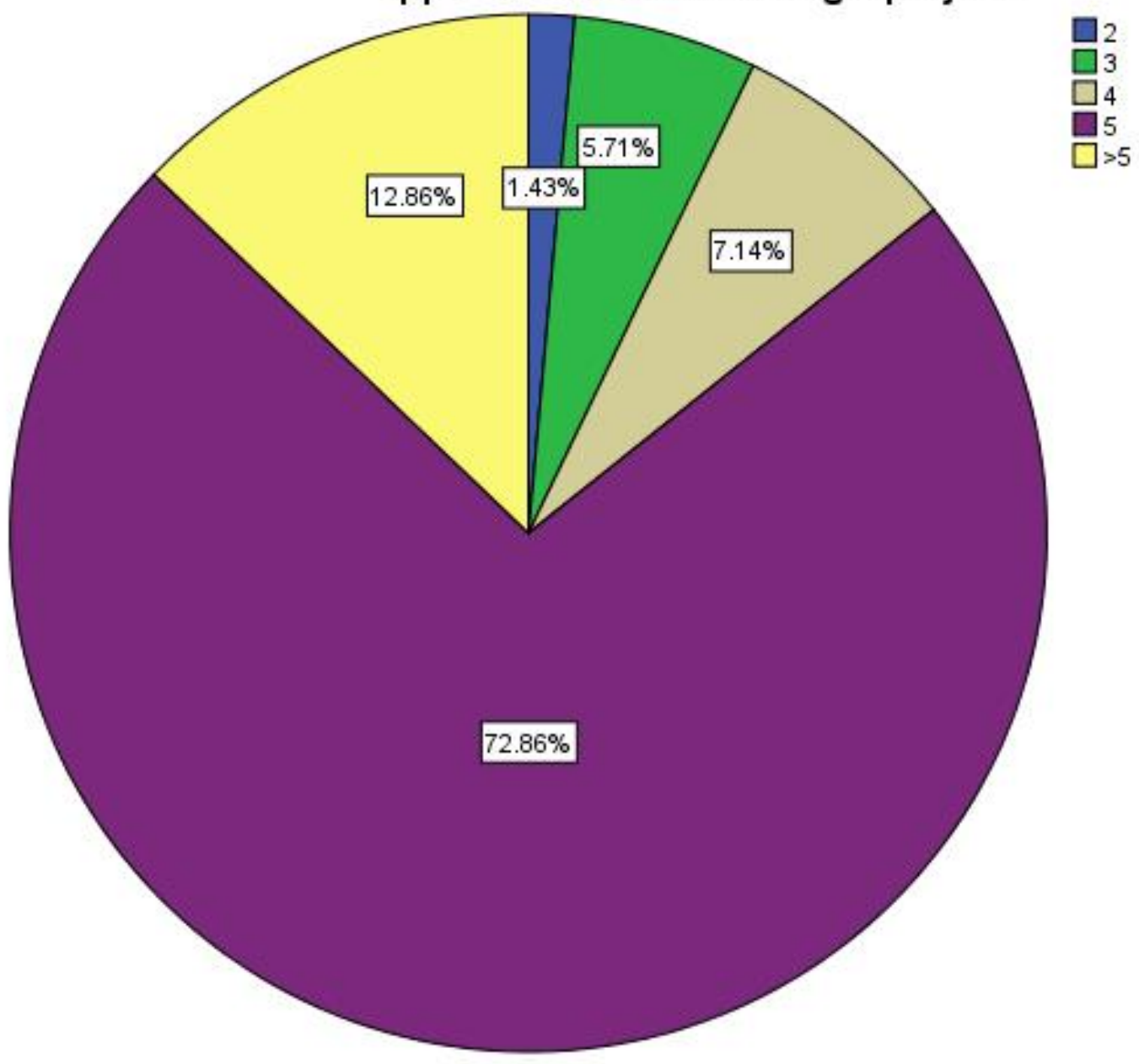

Figure 13. Average Governmental Stakeholders to be Approached for A Single Project

It can be derived from the above statistics that for each single project, the selected Companies must approach 5 governmental stakeholders for a single project and each stakeholder will take 3 weeks to grant one NOC. This will end up spending months just for waiting approvals/NOCs. This is confirming with a study conducted in Ghana where permit approval can take more than 3 months (Botchway et al. 2014). This is certainly impacting the construction duration and the estimated cost for the projects as confirmed by the Respondents' answers as shown in Figures 14 and 15. 
Is the process of obtaining NOClapproval from governmental bodies affecting your projects duration/schedule?

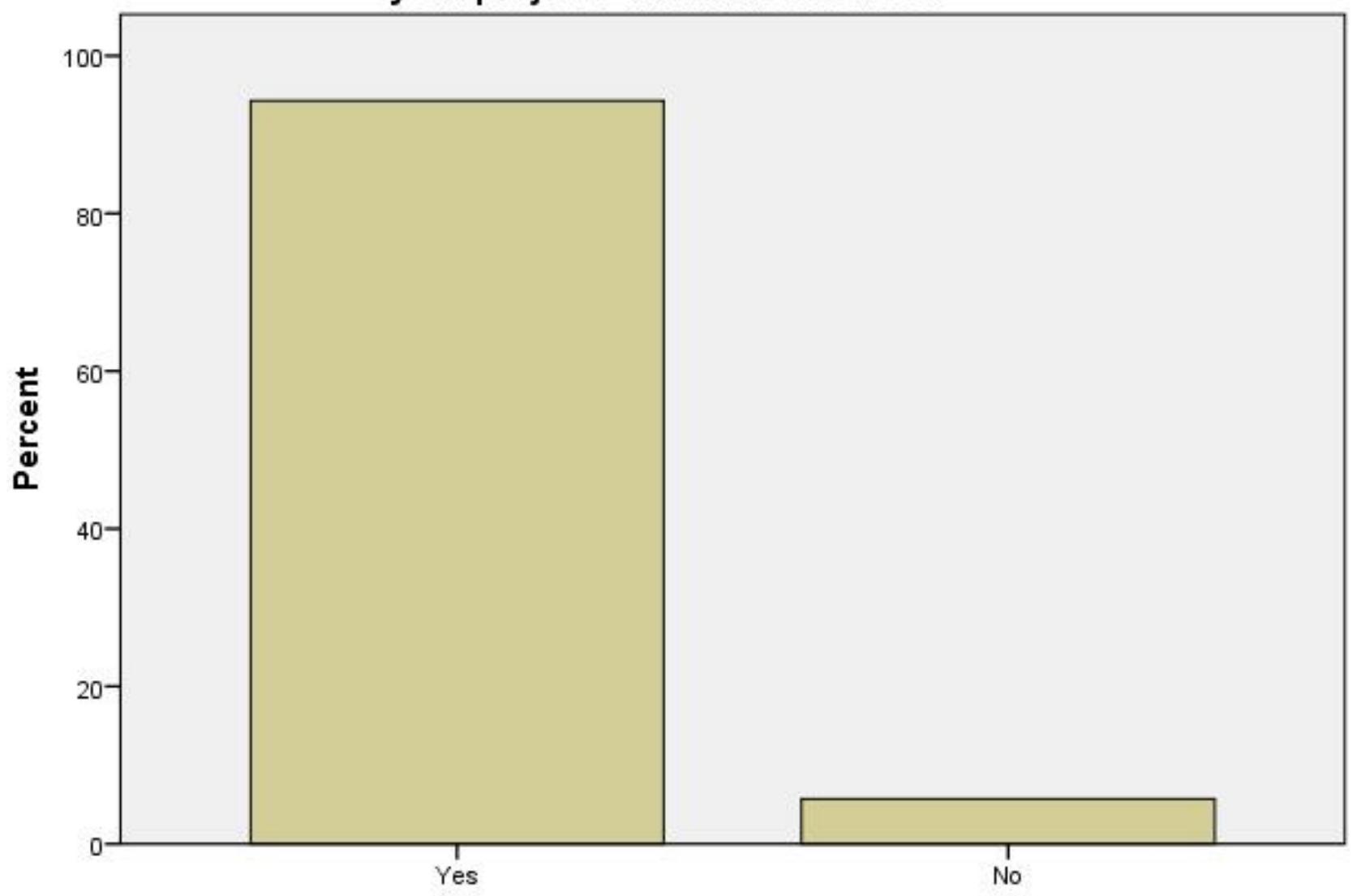

Is the process of obtaining NOClapproval from governmental bodies affecting your projects duration/schedule?

Figure 14. Approval Process Impacts on Projects' Duration 
Is there a cost impact on your projects due to lengthy governmental approval process?

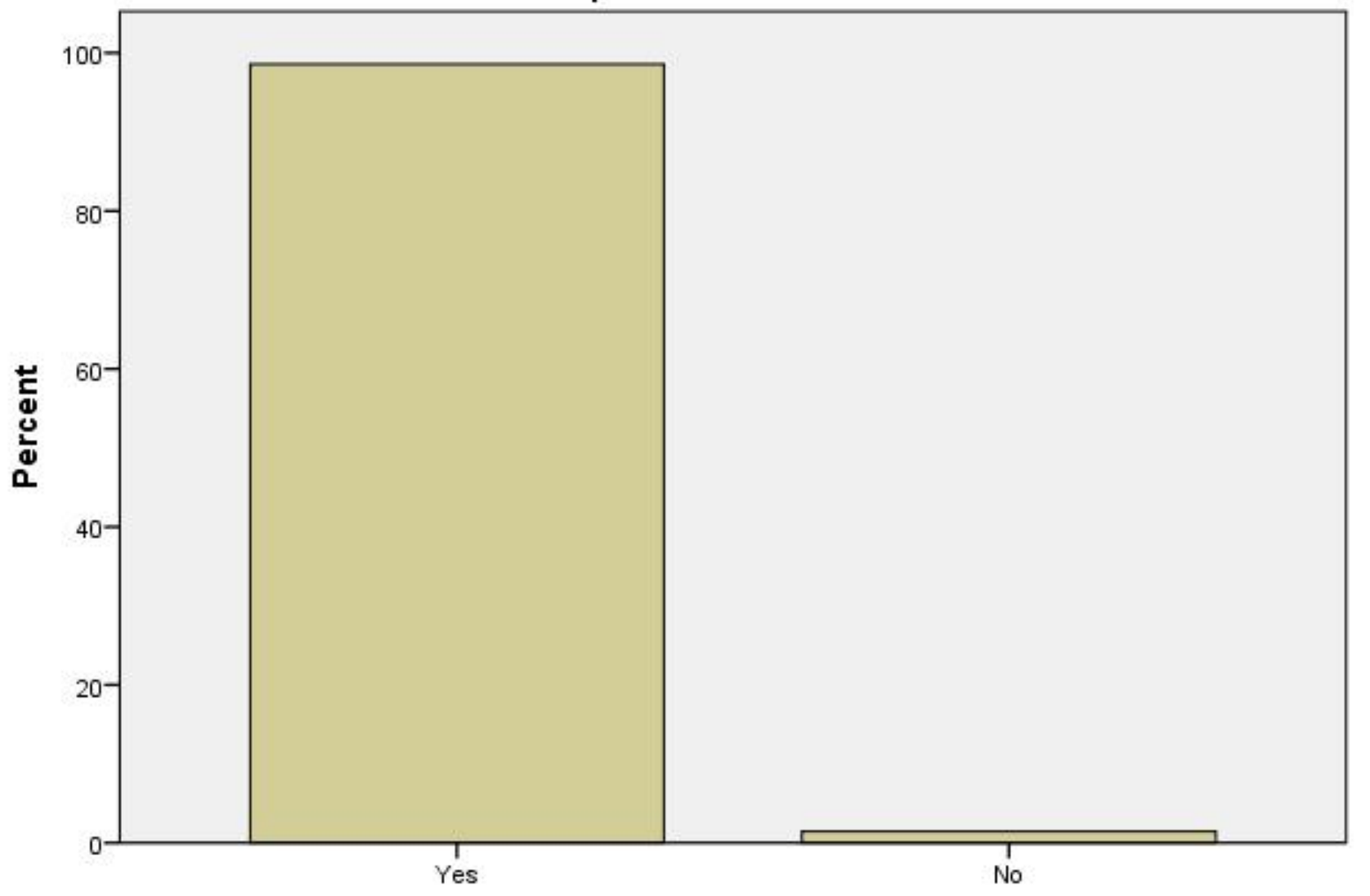

Is there a cost impact on your projects due to lengthy governmental approval process?

Figure 15. Approval Process Impacts on Projects' Cost

It is obvious from the charts above that most of selected Companies are suffering from the lengthy approval process as 98\% of the Respondents confirmed the impact on their projects' cost and $94 \%$ confirmed the impact of on their projects' schedule. (Agyeman and Kpamma 2014) confirmed that several approval processing steps, increased construction's cost and loss of project's value. Moreover, the requirements of governmental stakeholders are one of the reasons which affecting the approval process as those requirements are not enough clear for the Companies as shown in Figure 16. 


\section{Journal of Student Research}

\section{Are all the governmental stakeholders requirements for approval/NOCs requests are clear?}

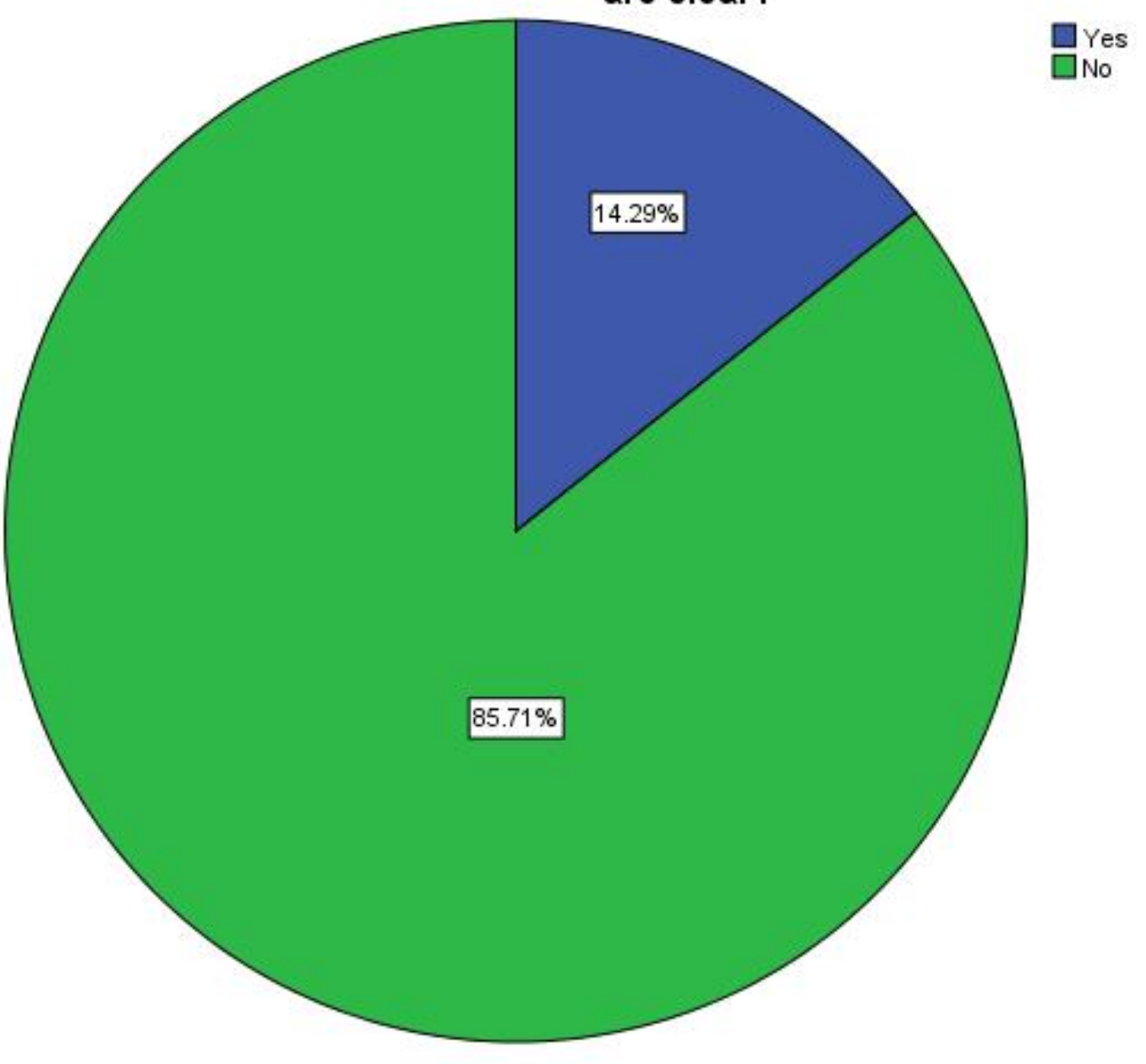

Figure 16. Governmental Stakeholders Requirement Clarity

From the chart above, $85.71 \%$ of the Respondents confirmed the unclarity of the governmental stakeholders' requirements. This demonstrates lack of coordination between governmental stakeholders and selected Companies as the requirements are not fully stated and cleared. The issue might be the provided requirements are inadequate or not explained enough. Besides, the requirements are not easy to fulfill, especially the Technical Requirements as found from the questionnaire answers analysis and demonstrated in Figure 17. 


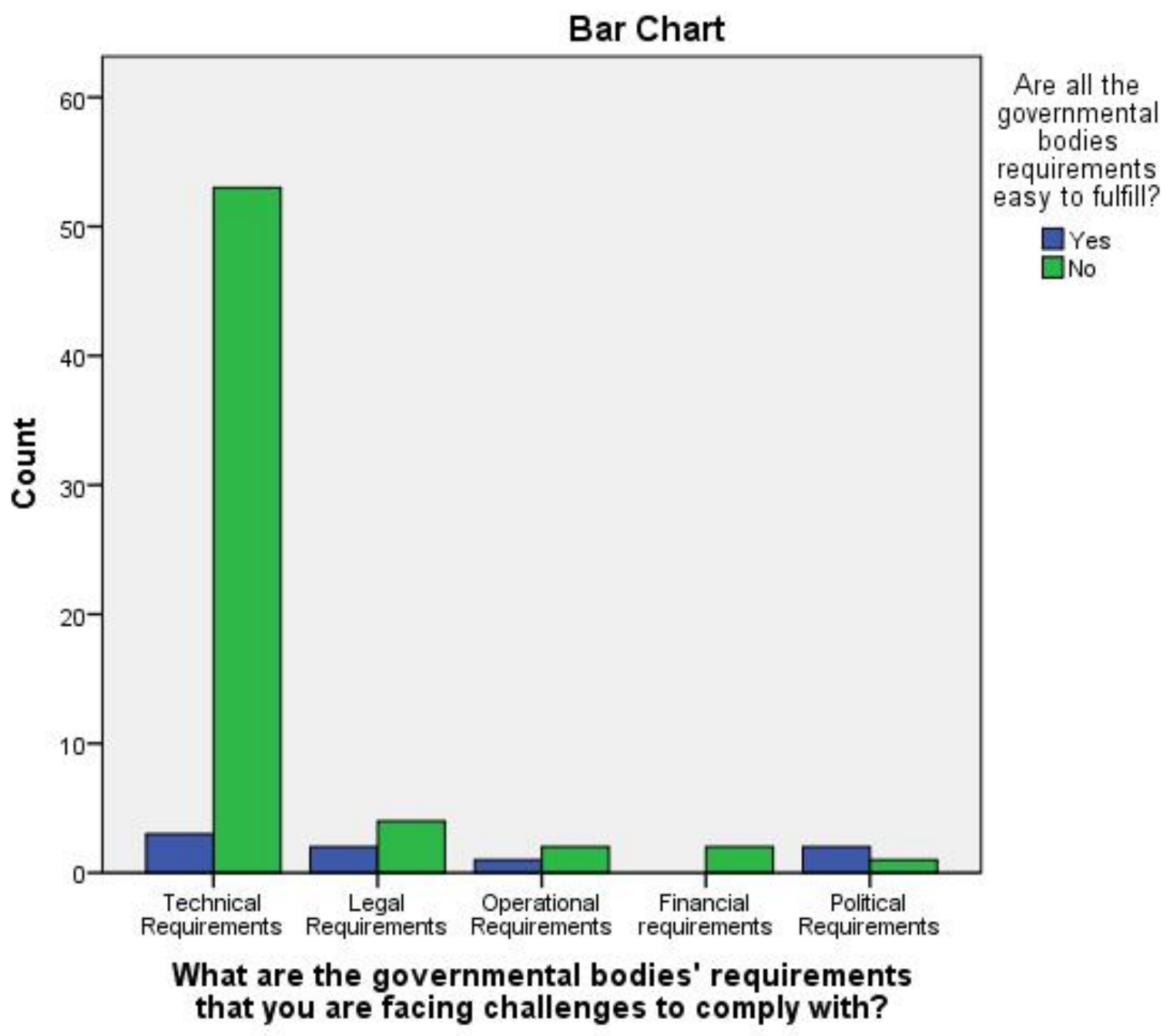

Figure 17. Governmental Stakeholders' Requirements and Fulfillment Difficulty

The chart above confirms that the governmental stakeholders' requirements are difficult to fulfill particularly the Technical Requirements as 56 Respondents confirmed the difficulty of complying with Technical Requirements where other requirements are exerting minimal challenges to the selected Companies.

\section{Quantitative Methodology Results - An Online Platform Solution}

Based on the questionnaire, the results are confirming the lengthy approval process of the governmental stakeholders where a solution shall be offered to improve the process and consequently the construction industry in Oman. Therefore, an online platform was developed where companies can apply for approval and NOCs and obtain the confirmation to go ahead with the construction in a short period. This platform is developed to be an Expert System and then measure the acceptance and compatibility of the platform by the field experts. As the Technical Requirements are the most challenging once, the platform designed to cover and make clear all the governmental stakeholders' requirements with focusing on the Technical Requirements. Also, the questionnaire's results revealed that plots and permits related authority and environment related authority are the most governmental stakeholders which the Respondents emphasize on developing their approval process and implement an online platform. 


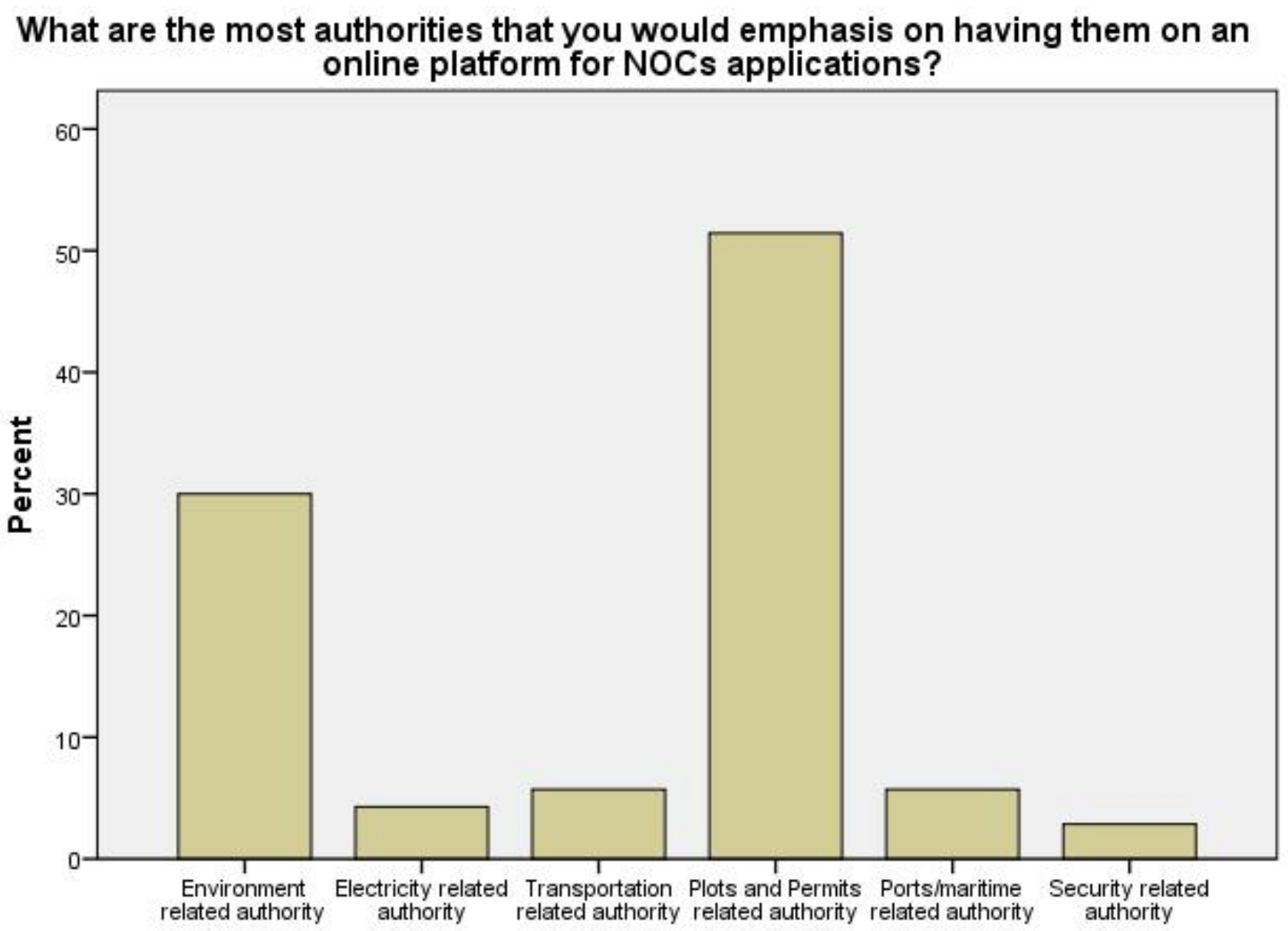

What are the most authorities that you would emphasis on having them on an online platform for NOCs applications?

Figure 18. Authorities to Adopt Online Platform for NOCs

Figure 18 demonstrates that 36 Respondents out of 70 confirmed the need to have an online platform which will accelerate the approval process for plots and permits related authority. (Agyeman and Kpamma 2014) confirmed the success of an online platform (One-Stop-Shop) as the average success rate was $84 \%$ for 453 approval applications in study conducted at Ghana.

Based on the questionnaire's answers analysis, it was found that there is a necessity to develop an online application platform. This is according to three key factors:

\section{The Location Factor}

Table 4 below is a capture from the SPSS output which explains that 45 Respondents having projects located in Muscat Governance where the remaining 25 Respondents having projects outside Muscat. But, 63 of the total Respondents must travel to Muscat seeking for NOCs and approvals. This is a time wasting for the Respondents traveling from time to time to meet with governmental stakeholders. Having an online application platform would bridge the location gap and would make the process easy to apply an application online. 


\section{Please select at what Governance your Projects normally located? * Please select at what Governance your governmental stakeholders normally located where you are seeking for approval/NOCs? Crosstabulation}

Count

\begin{tabular}{|c|c|c|c|c|c|c|}
\hline & & \multicolumn{4}{|c|}{$\begin{array}{l}\text { Please select at what Governance your governmental stakeholders } \\
\text { normally located where you are seeking for approval/NOCs? }\end{array}$} & \multirow[b]{2}{*}{ Total } \\
\hline & & Muscat & Al Wusta & Al Batinah & Musandam & \\
\hline \multirow{7}{*}{$\begin{array}{l}\text { Please select at what } \\
\text { Governance your Projects } \\
\text { normally located? }\end{array}$} & Muscat & 45 & 0 & 0 & 0 & 45 \\
\hline & Al Wusta & 4 & 2 & 0 & 0 & 6 \\
\hline & Al Sharqiyah & 5 & 0 & 0 & 0 & 5 \\
\hline & Al Batinah & 4 & 0 & 4 & 0 & 8 \\
\hline & Musandam & 2 & 0 & 0 & 1 & 3 \\
\hline & Dhofar & 2 & 0 & 0 & 0 & 2 \\
\hline & Ad Dakhiliyah & 1 & 0 & 0 & 0 & 1 \\
\hline Total & & 63 & 2 & 4 & 1 & 70 \\
\hline
\end{tabular}

Figure 19. Respondents Projects' Locations

Moreover, only 7 Respondents were able to obtain approvals from the same area where their projects are located. Those projects are in Al Wusta, Al Batinah and Musandam. But in general, the Project Managers shall travel to Muscat in order to solve the conflicts with the governmental stakeholders where in the situation of the 7 Respondents, there might be small issues and they managed to solve within the governmental office which located in the same projects' area.

\section{The Time Factor}

As shown in Table 5, 7 Respondents who are working on the Top Management in the selected Companies confirmed the need of optimizing the time of NOCs/approvals process. Also, 28 Project Managers agreed that the current process is length and taking long time.

\section{What is your position? * Current established process of obtaining NOCs/approvals from governmental stakeholders is lengthy and shall be optimized Crosstabulation}

Count

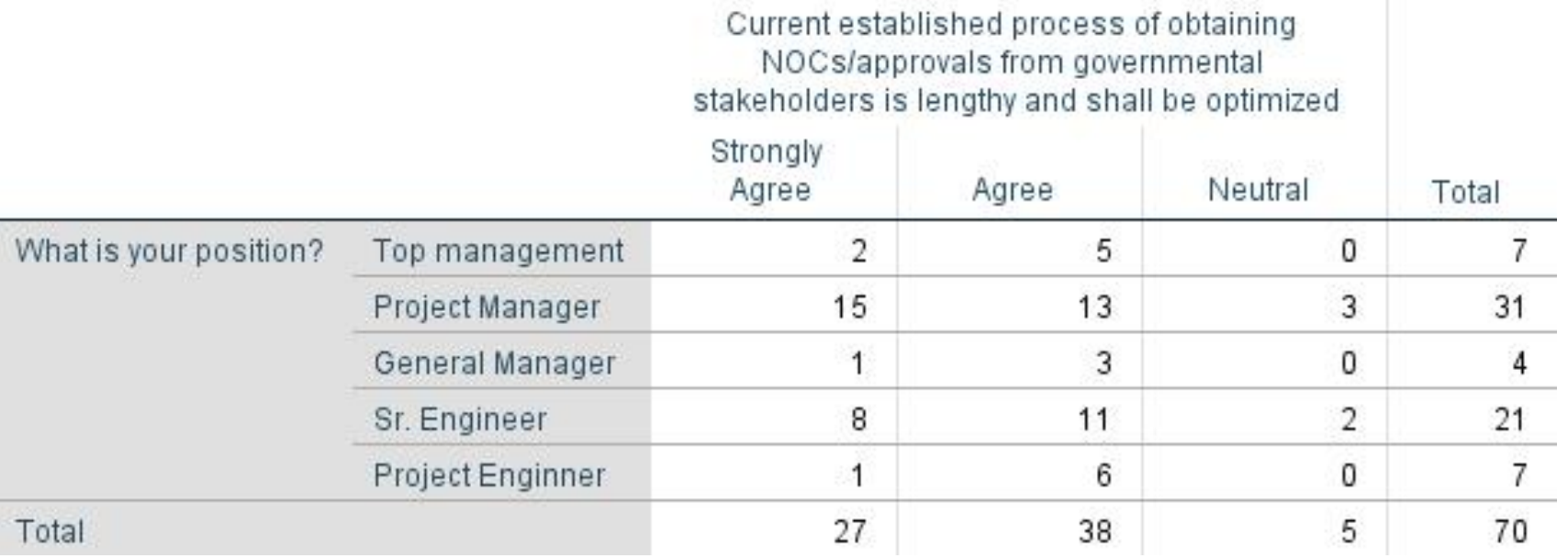

Figure 20. Respondents Confirmed the Need of Optimizing Approval Process 
In addition, 21 Senior Engineers would like to optimize the approval process time. These findings confirm that the Time Factor is critical for those Managers and Top Management. Hence, introducing the online application platform would slash the time waisted in the paper works and bureaucracy process.

\section{The Services Factor}

As shown in Figure 19, despite there are online services which available from the governmental stakeholders but still they are not helping in accelerating the NOCs issuance. With this regard, $15.71 \%$ of Respondents answered "Agree" and 62.86\% answered "Strongly Agree". One of the reasons which might lead to this conclusion is that the available online requirements of the governmental stakeholders for NOCs/approval application are not complete and unclear. This was clear in the results discussed in Section 5.1.2 of this report.

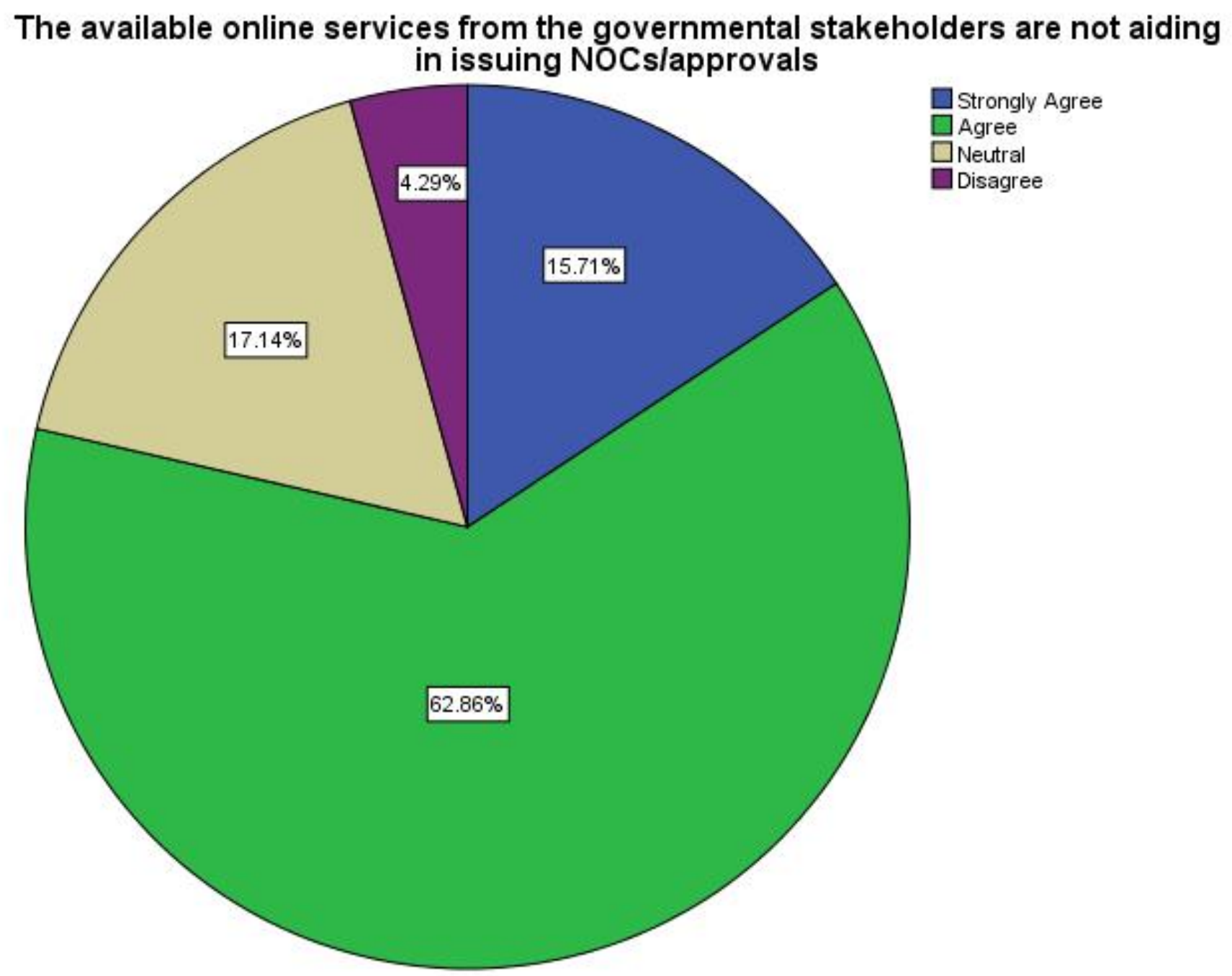

Figure 21. Governmental Stakeholders' Online Services for Issuing NOCs

In the other hand, $4.29 \%$ of Respondents answered "disagree" that the current governmental stakeholders' online services are not aiding in issuing the NOCs and approvals. This might be due to the project's type. Because $4.29 \%$ are having trade facilitation projects which requires minimal approvals which already available within the governmental stakeholders. 


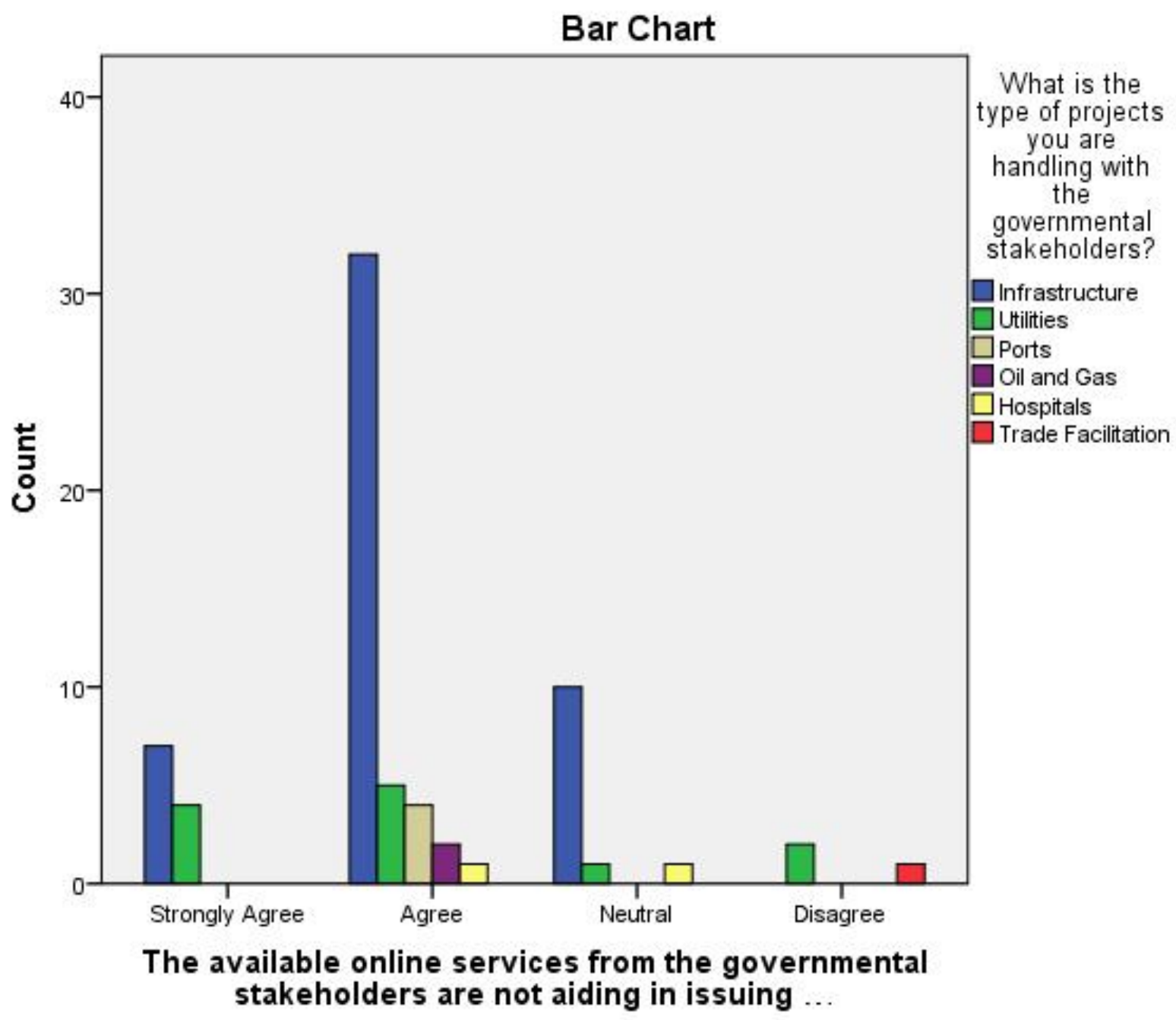

Figure 22. Respondents Project Type and Online Services

As a conclusion for the service factor, an online platform for NOCs/approval application shall be developed to improve the services in which will expedite the process. This platform shall contain all the governmental stakeholders' requirements and must be designed to be user-friendly.

All in all, the above main three factors are the main drivers for the decision made to design a platform where they consider the location, time and service quality. Because the results have revealed how the selected Companies are suffered from the time waisted in waiting approvals due to lack of quality online services and vague requirements. The platform has been designed and the acceptance level of developing such online services was high from the Respondents as will be discussed in the next Section.

An Expert System has been developed based on the high acceptance of Respondents answers as they confirmed the need to implement an online platform for NOCs application where governmental stakeholders' requirements are clearly stated, and application process is straightforward. Figure 21 confirms the acceptance of the Respondents to adopt the Expert System. 


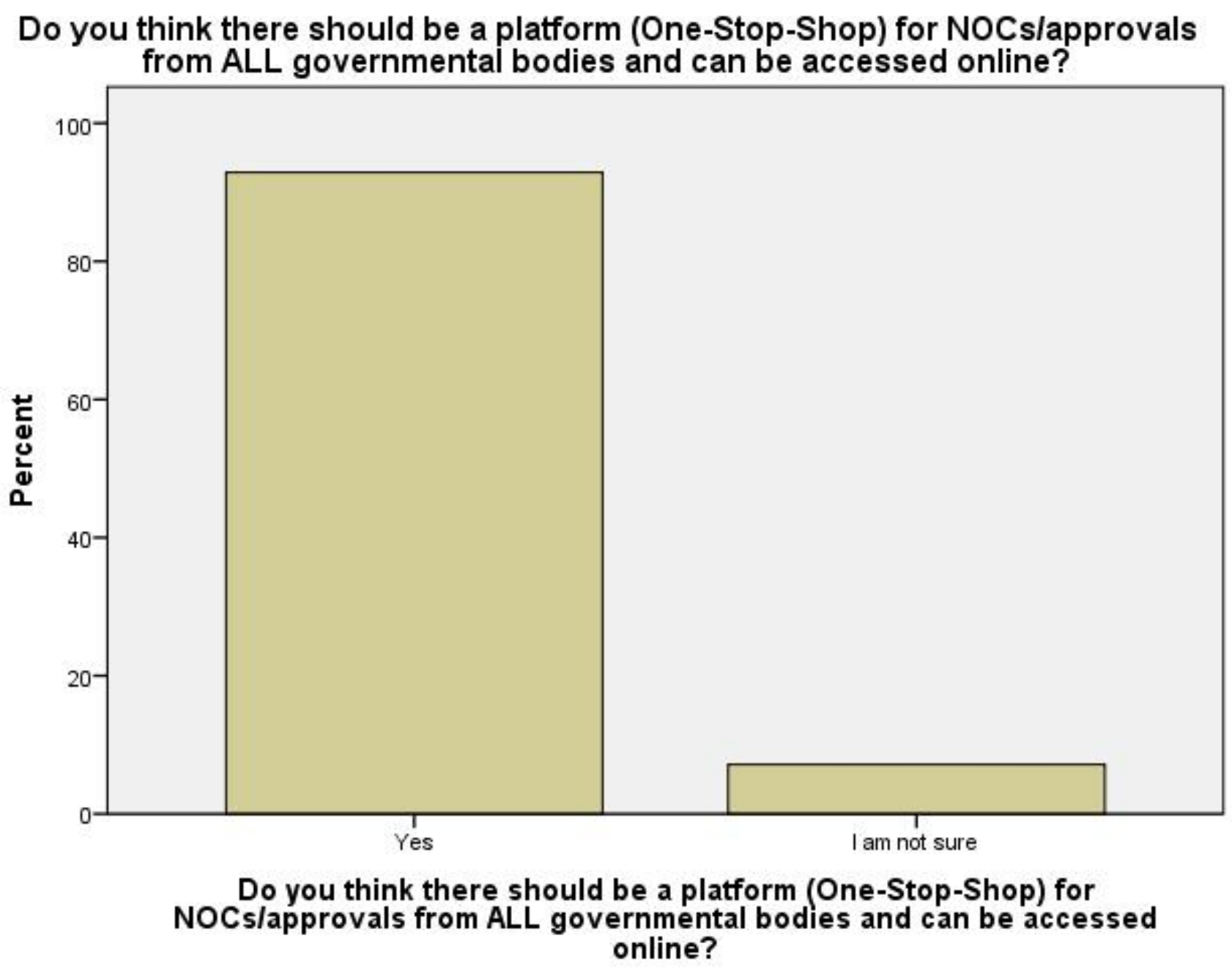

Figure 23. Respondents' Confirmation for Implementing an Online Platform

Based on the results, 93\% of the Respondents would like to have an online application platform. In the other hand, $7 \%$ are not sure if this online system should be implemented or not.

In addition, those Respondents confirmed that the online platform is expediting the NOCs process and therefore the projects' completion as shown in Figure 22. 


\section{Do you think having an online NOCs/approval application platform for your projects would help in expediting your projects completion?}

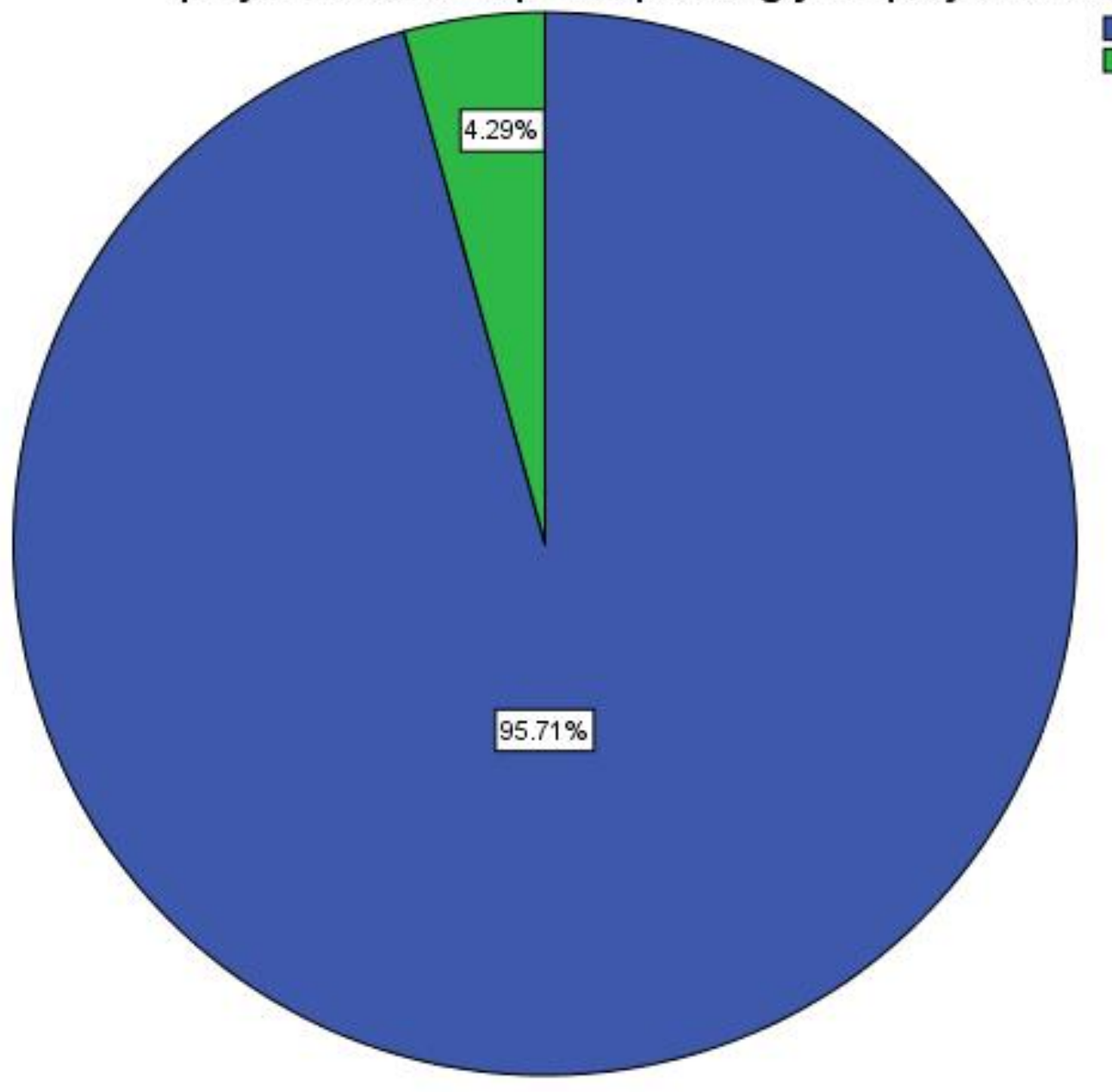

Figure 24. Respondents Confirmed the Benefit of an Online Platform

Furthermore, Figure 22 considers the time factor which was discussed in Section 5.1.3.2 as 95.71\% of the Respondents agree that the designed platform is slashing the duration of their projects. Finally, to check the results' reliability for the Questionnaire, a reliability analysis has been performed via SPSS, and Cronbach's Alpha found to be 0.712. Table 5 is SPSS output showing the analysis results.

\begin{tabular}{|l|l|}
\hline \multicolumn{2}{|c|}{ Reliability Statistics } \\
\hline Cronbach's Alpha & Cronbach's Alpha Based on Standardized Items \\
\hline .712 & .700 \\
\hline
\end{tabular}

Table 3. Cronbach's Alpha for the Research's Results

\section{Qualitative Methodology Results - General Analysis}

After recording the scripts and responses of the interviews, the answers were reviewed and links among the Interviewees answers were found using different codes and charts. The Interviewees details are listed in Table 6 below:

\begin{tabular}{|l|l|l|l|}
\hline No. & Position & Company & Project \\
\hline & & & \\
\hline
\end{tabular}


Journal of Student Research

Fourth Middle East College Student Research Conference, Muscat, Sultanate of Oman

\begin{tabular}{|l|l|l|l|}
1 & Construction Manager & CCC & Road Project \\
\hline 2 & Senior Contracts Engineer & ASYAD & Hospital Project \\
\hline 3 & Construction Manager & INSHA & Road Tunnels Project \\
\hline 4 & General Manager & Marafi & Port Project \\
\hline 5 & Assistant Project Manager & INSHA & Hospital Project \\
\hline 6 & Technical Manager & Marafi & Port Project \\
\hline 7 & Development Manager & Khimji Ramdas & Port Project \\
\hline 8 & Stakeholder Manager & Marafi & Port Project \\
\hline 9 & Ports Director & Asyad & Infrastructure \\
\hline 10 & General Manager & Marafi & Port Project \\
\hline
\end{tabular}

Table 4. Interviewees Details

The process of analyzing the interview responses is illustrated in the flow-chart at Figure 23.

\section{Governmental Stakeholders Impacts on}

Construction Projects in Oman - Research

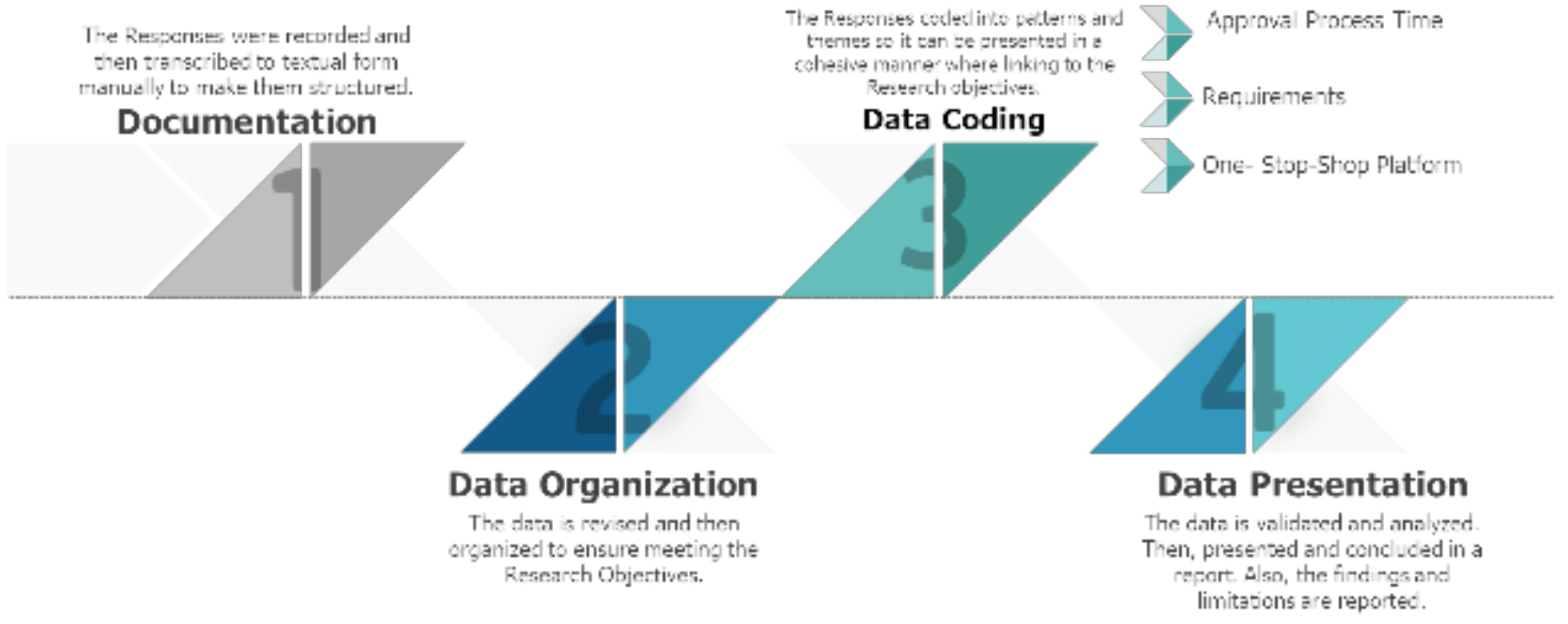

Figure 25. Interviews Analysis Process

After coding the data into three Themes, then the data was analyzed, and results were recorded. The results are presented in the next Section.

\section{Qualitative Methodology Results - Interview Results}

Most Respondents showed a dissatisfaction from the approval process duration taken by the governmental stakeholders to issue NOCs/approvals. There is a high tendency to improve the process so it can take less time. The dissatisfaction is coming from the waisted time spent in waiting approval issuance and extra costs which payed due to operational expenses. Table 7 demonstrates the results revealed from the interview records.

\begin{tabular}{|l|l|l|l|}
\hline \multirow{2}{*}{ Respondents/Satisfaction } & \multicolumn{3}{|c|}{ Approval Time Process Satisfaction } \\
\cline { 2 - 4 } & Dissatisfy & Satisfy & Neutral \\
\hline Respondent No. 1 & $\mathrm{X}$ & & \\
\hline Respondent No. 2 & $\mathrm{X}$ & & \\
\hline Respondent No. 3 & & & $\mathrm{X}$ \\
\hline
\end{tabular}


Journal of Student Research

Fourth Middle East College Student Research Conference, Muscat, Sultanate of Oman

\begin{tabular}{|l|l|l|l|}
\hline Respondent No. 4 & $\mathrm{X}$ & & \\
\hline Respondent No. 5 & $\mathrm{X}$ & & \\
\hline Respondent No. 6 & $\mathrm{X}$ & & \\
\hline Respondent No. 7 & $\mathrm{X}$ & & \\
\hline Respondent No. 8 & $\mathrm{X}$ & & \\
\hline Respondent No. 9 & $\mathrm{X}$ & & \\
\hline Respondent No. 10 & $\mathrm{X}$ & & \\
\hline
\end{tabular}

Table 5. Approval Time Process Satisfaction

To summarize the Table above, 9 Respondents had showed a dissatisfaction toward the approval time. Only 1 Respondent had a Neutral answer regarding the time, and this is derived from the interview conducted with him. Based on these results, there is a need to improve the time and this conclusion is confirming the Quantitative methodology results presented in Section 4.1.3.2 above where Respondents confirmed the need to improve the Time Factor. Moreover, the Respondents demonstrated the impact on the projects' cost due to the lengthy approval process as shown in Table 8 below.

\begin{tabular}{|l|l|l|l|}
\hline \multirow{2}{*}{ Respondents/Cost Impact } & \multicolumn{3}{|c|}{ Cost Impact Confirmation Due to Lengthy Approval Process } \\
\cline { 2 - 4 } & Yes & No & Maybe \\
\hline Respondent No. 1 & $\mathrm{X}$ & & \\
\hline Respondent No. 2 & $\mathrm{X}$ & & $\mathrm{X}$ \\
\hline Respondent No. 3 & & & \\
\hline Respondent No. 4 & $\mathrm{X}$ & & \\
\hline Respondent No. 5 & $\mathrm{X}$ & & \\
\hline Respondent No. 6 & $\mathrm{X}$ & & \\
\hline Respondent No. 7 & $\mathrm{X}$ & & \\
\hline Respondent No. 8 & $\mathrm{X}$ & & \\
\hline Respondent No. 9 & $\mathrm{X}$ & & \\
\hline Respondent No. 10 & $\mathrm{X}$ & & \\
\hline
\end{tabular}

Table 6. Cost Impact Confirmation Due to Approval Process

The results above were extracted from the responses and it is obvious that the Respondents are suffering from spending extra costs due to the lengthy approval process. This is another evident which confirms the importance of having a solution that able to slash the approval time.

The requirements of the governmental stakeholders are one of the challenges that encountering the companies who are working on the construction industry in Oman. This fact can be recognized from the Interviewees responses which confirmed with the Quantitative methodology results in Section 5.1 above. Majority of answers through the interviews confirmed the problem with the requirements and its consequences. Figure 24 which concluded from the Interviewees summarize the Interviewees responses. 


\section{Companies Challenges Chart- Requirements Theme}
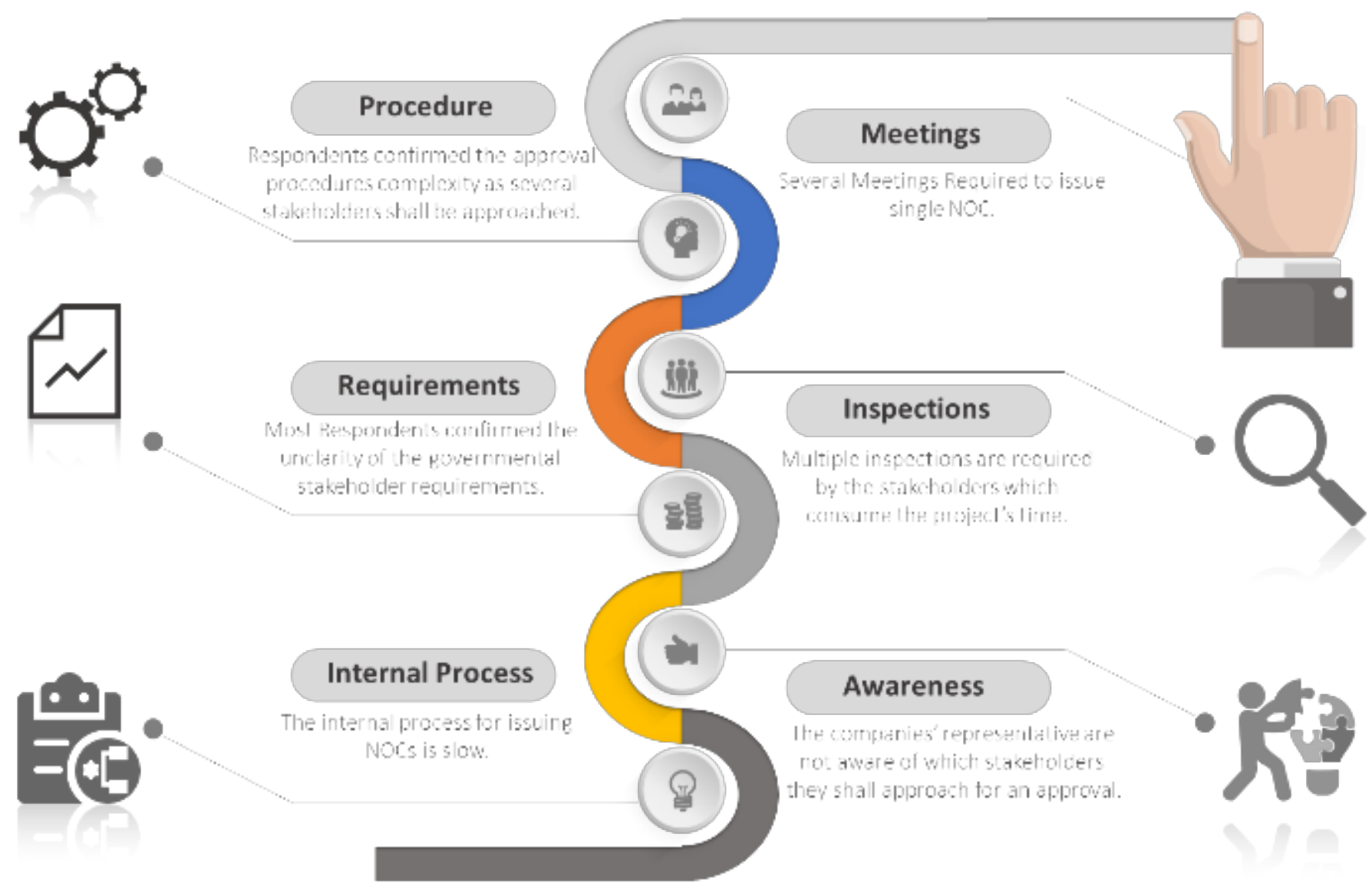

Figure 26. Requirements Theme - Challenges due to Governmental Stakeholders

Requirements Theme coded into Six patterns based on the Interviewees answers. These requirements always lead to delay the construction program. The most challenging patterns are that the requirements are not clear for the companies and the procedure itself is complicated where multiple inspections and authorities are required to approve a single NOC. As a result, the process shall be developed to make clear the requirements and develop an integration unit where all approvals can be sought from there. In the next Theme, the Interviewees insisted to introduce an integrated single point for NOCs/approvals applications.

All Interviewees demonstrated the well to improve the approval process so it can be done in a short time and less cost. An integrated single point where the companies can apply for approvals/NOCs is the most solution that preferred by the Interviewees. In this single point, all Governmental Stakeholders' requirements must be clear, and the approval procedure has to have a smooth sequence. Also, regulations shall be established where these stakeholders must response to the application request in a specified short time. This integrated single point shall work as One-StopShop online platform which covers the Governmental Stakeholders and their requirements. Table 9 summarizes the Interviewees' answers and their recommendations. 


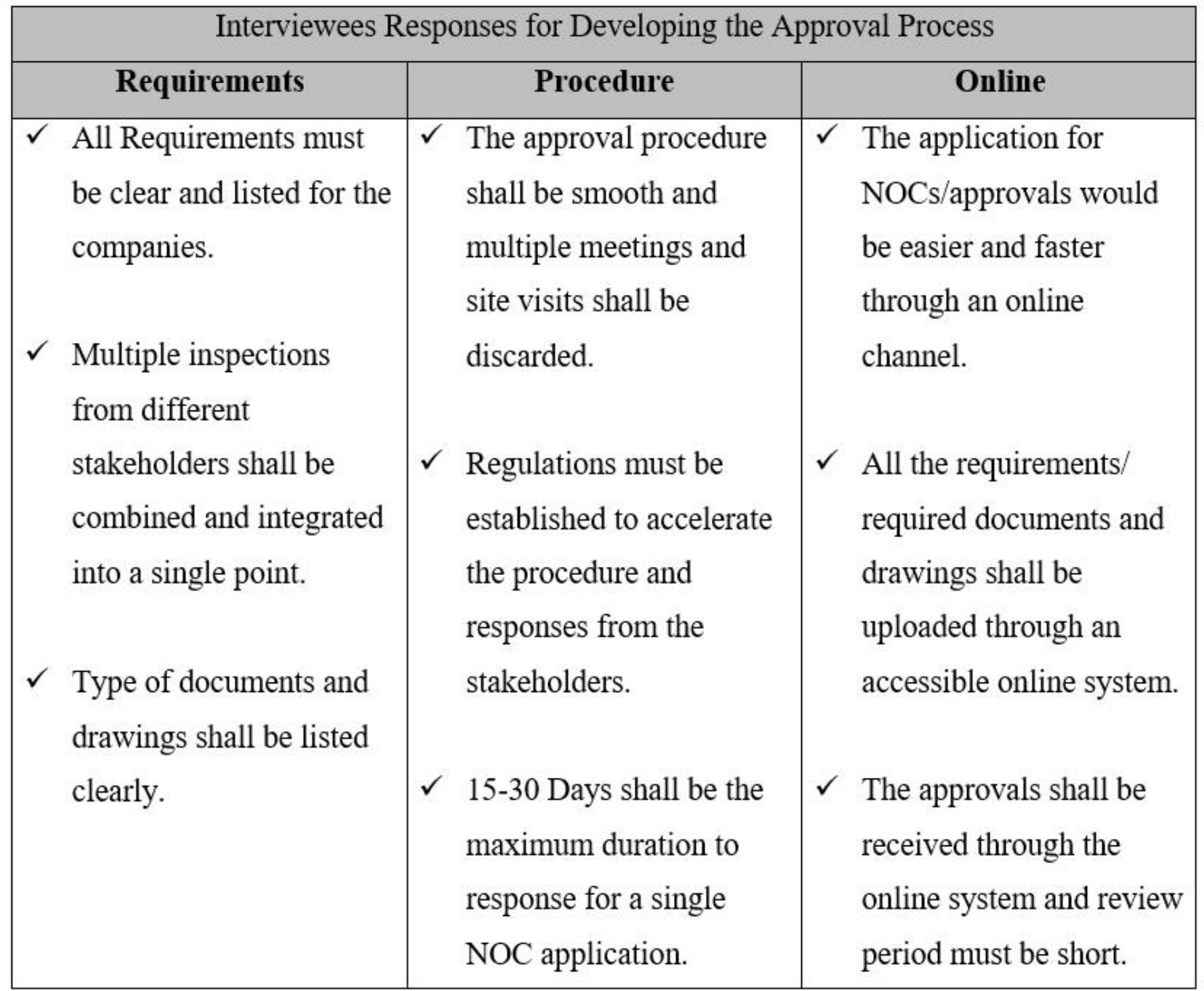

Figure 27. Interviewees Responses for Improving Approval Process

Everyone participated in the interviews agrees on the importance of emerging the current established approval process through an online platform. This is confirming with the study's results conducted in Sweden where most interviewees showed a keen interest for one-stop-shop and would have a positive impact on the market (Pardalis et al. 2019). Therefore, an Expert System was developed to work as an online application platform and the outcomes of that will be discussed in next Section.

\section{Expert System Methodology Results}

The Expert System evaluated using specific questions in the questionnaire. The system evaluated by different personnel from the selected Companies for this Research. The platform got high acceptance by the evaluators at first run of the platform pilot. Based on the results, 93\% of the Respondents confirm the importance to adopt the platform officially within the governmental stakeholders' systems. Besides, they confirmed that online platform is accelerating the process of granting NOCs and approvals. Moreover, the Respondents agree that this system is making the governmental stakeholders' requirements clear and easy to request/apply for approvals. This is apparently due to the clear platform interface and different features which built within the system. The responses are categorized into three elements as illustrated in findings chart (Figure 25) of the 
Expert System.

\title{
Expert System (Online Platform) Findings Chart
}

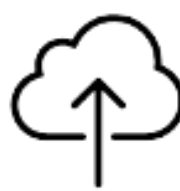

\author{
SYSTEM IMPLEMENTATION
}

Majorityy of Respondents agree to implement the online platform.
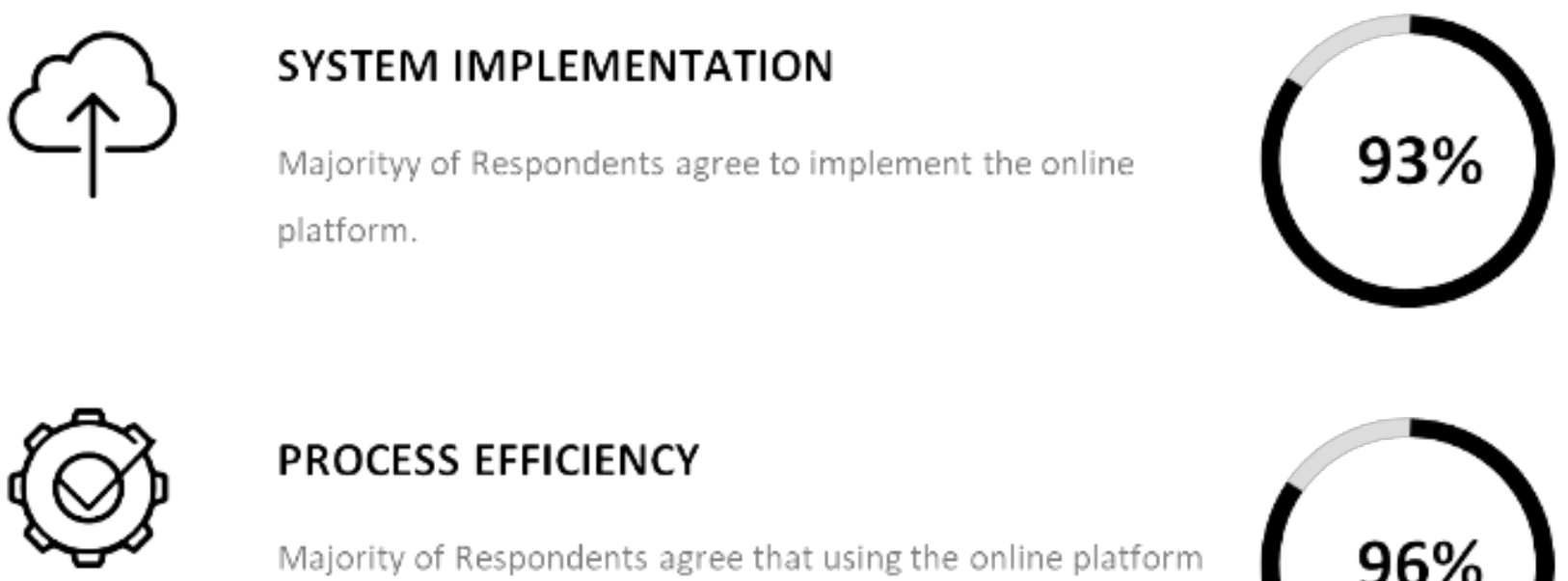

\section{PROCESS EFFICIENCY}

\section{Majority of Respondents agree that using the online platform is improved the approval process and made it faster.}
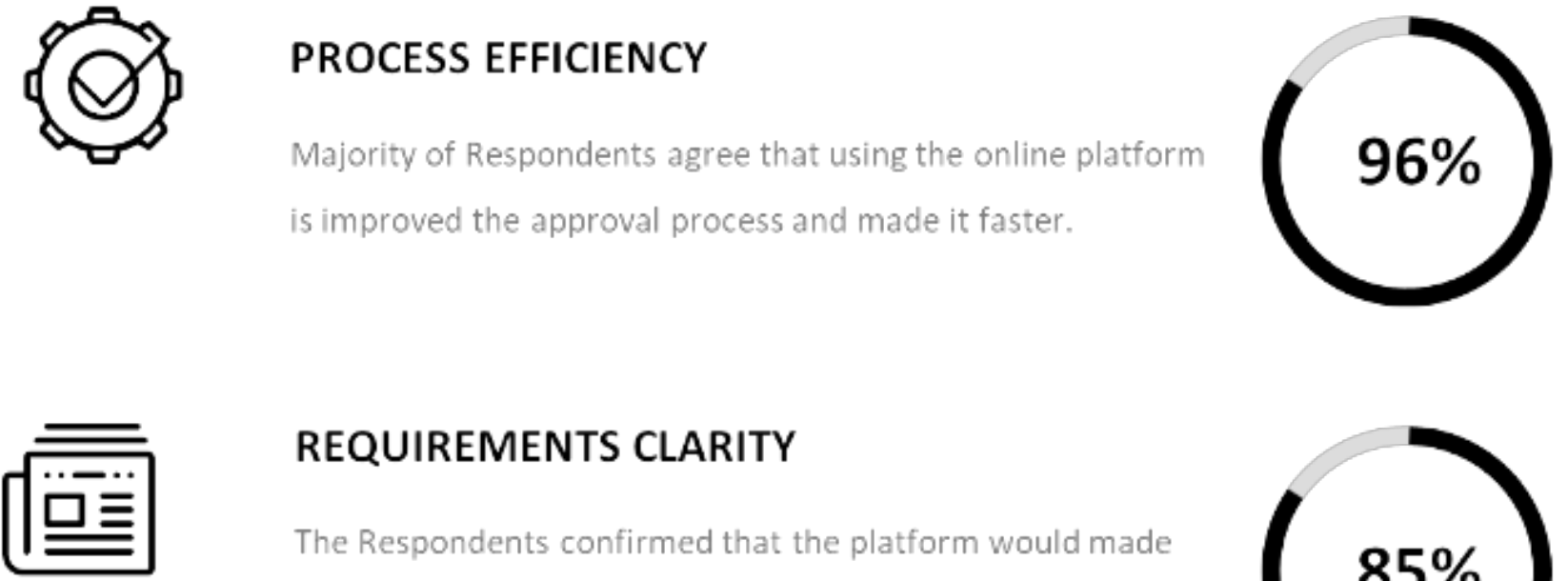

\section{REQUIREMENTS CLARITY \\ The Respondents confirmed that the platform would made the governmental stakeholders clear and misunderstanding is avoided.}

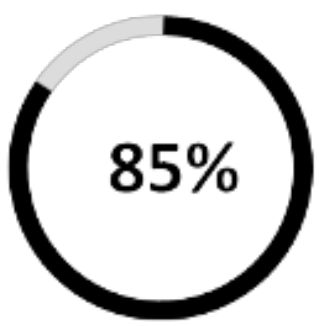

Figure 28. Expert System Findings Chart

The chart explains how the positive impact created by the platform as it made the process smooth and requirements clear. High parentages of Respondents demonstrated the acceptance of the system. These high percentages confirmed the success of such solutions which promotes integrations among companies and governmental stakeholders. (Molfetas and Wille 2018), confirmed in their survey that the solution which supports the online information exchange and services got high percentage which is $85 \%$.

\section{Conclusion}

Governmental stakeholders are very crucial part in construction industry within Oman which might lead projects to success or delay. Lengthy approval process required by these stakeholders are hindering the construction progress in several projects in Oman. This paper studies the impact of slow approval process established within government stakeholders and a solution using Expert System method with an aim at improving approval process. The objectives of this Research were met using three Research methodologies which are quantitative, qualitative and expert system. More than 15 papers reviewed and used for the Research. 


\section{Journal of Student Research}

Fourth Middle East College Student Research Conference, Muscat, Sultanate of Oman

The Research's outcomes revealed that approval process is slow and requires optimization. The average duration for single approval takes minimum two weeks and can go more than four weeks. The main reason of the delay was that the internal approval process of the stakeholders is slow and complicated. Also, the numbers of stakeholders which require approvals for a single NOC are 5 or more. Besides, it was found that the stakeholder's requirements are not clear enough for the Companies particularly technical requirements which will end up in wasting time for several meetings. This requires multiple meetings and visits to grant a single NOC. In light of previous study conducted by (Agyeman and Kpamma 2014), apparently, this is impacting projects' cost and time as found in the quantitative and qualitative methods of this Research.

An Expert System (online platform) was developed to work as One-Stop-Shop of the approval process as majority of Respondents showed a keen interest in adopting the platform based on three factors which are location, time and services. The platform got high acceptance from the evaluators which found to be efficient and optimizing the approval process time. (Levine and Cook 2016), found the same in their technical report as 43 States in U.S. developed One-Stop-Shop for approval applications and the process time was reduced significantly. This also allow to direct personnel to perform other tasks which resultant into cost savings.

At this level of study and due to time constraint for delivering the Research, only 10 Individuals have been interviewed. To assure the results' reliability of the Qualitative methodology, more candidates who are working on the construction sector in Oman and dealing with governmental stakeholders shall be interviewed.

Moreover, despite the reliability of the Quantitative results were acceptable and the Research covered different 6 companies who are considered at the top companies in the field, still the Research area should cover more companies in the sector. This would increase the reliability of the Research and new solution might reveal.

Furthermore, the developed Expert System has been checked and validated by few experts and employees in construction sector. The system should be experienced by several users who are dealing with governmental stakeholders to verify the maximum compatibility with the government stakeholder management system. Too, a dedicated research to measure the acceptance of the platform shall be conducted for further compatibility and acceptance assurance. Also, it should be sponsored by one of the government entities to adopt and maintain the system regularly. The system is already offered to Tanfeedh (Implementation Support and Follow-up Unit-Oman) and their acceptance to adopt the system shall be pursued.

\section{Acknowledgements}

The research was conducted in collaboration with the Department of Civil Engineering, Middle East College/ Knowledge Oasis Muscat, Oman

\section{References}

Abdelhamid, A. (2019) Governmental Stakeholders' Impacts on Construction Projects due to Lengthy Approval Process [letter] to AlAdawi, O. [08 August 2019]

Agyeman, S. and Kpamma, Z. (2014) Challenges in the Processing of Building Permits in Ghana - $a$ Precursor for Development of Illegal Structures. 'Proceedings of the 7th Annual International Applied Research Conference'. held 07- 09 July 2014 at Ghana. koforidua: Koforidua Technical University

Akinyemi, A., Sun, M. and Gray, A. (2018) 'An Ontology-Based Data Integration Framework for Construction Information Management'. Proceedings of The Institution of Civil Engineers - 


\section{Journal of Student Research}

Fourth Middle East College Student Research Conference, Muscat, Sultanate of Oman

\section{Management, Procurement and Law 171 (3), 111-125}

Ali, K., Mazen, S. and Hassanein, E. (2018) 'A Proposed Hybrid Model for Adopting Cloud Computing In E-Government'. Future Computing and Informatics Journal 3 (2), 286-295

Botchway, E., Afram, S. and Ankrah, J. (2014) 'Building Permit Acquisition in Ghana: The Situation in Kumasi'. Developing Country Studies 4 (20), 11-22

Chan, A. and Oppong, G. (2017) 'Managing the Expectations of External Stakeholders in Construction Projects'. Engineering, Construction and Architectural Management 24 (5), 736-756

Costanzo, E., McElroy, D., Rivers, W., Androutsopoulos, A., Spanou, A., Altmann, N., Gomez, V., Fragoso, R., Fernandes, J., Hoogelander, K., Jambor, E. and Wnuk, R. (2017) Stakeholder Engagement Final Report No. D5.6 -5.7. Brussels: European Union

Cotton, M. and Mahroos-Alsaiari, A. (2014) 'Key Actor Perspectives on Stakeholder Engagement in Omani Environmental Impact Assessment: An Application Of Q-Methodology'. Journal of Environmental Planning and Management 58 (1), 91-112

Fageha, M. and Aibinu, A. (2016) 'Identifying Stakeholders' Involvement That Enhances Project Scope Definition Completeness in Saudi Arabian Public Building Projects'. Built Environment Project and Asset Management 6 (1), 6-29

ISFU (2017) Annual Report 2017: Logistics, Tourism, labor, Manufacturing and Finance. Muscat: ISFU

Jaiswal, B. (2018) 'Effective Electronic Governance for Good Governance in India'. Journal of Public Policy and Environmental Management 2 (1), 12-21

Joshi, P., Islam, S. and Islam, S. (2017) 'A Framework for Cloud Based E-Government from The Perspective of Developing Countries'. Future Internet 9 (4), 80

Ladin, M., Liew, F., Harith, N., Yung, L., Jaimin, F. and Yahia, H. (2019) Development of Accident Expert System Manager (AESM) As A Learning Tool for Students. 'Conference on Innovation in Education for Global Business'. held 24-26 June 2019 at University Malaysia Sabah. Kota Kinabalu: University Malaysia Sabah

Levine, A. and Cook, J. (2016) A Report on Transportation of Large Wind Components: A Permitting and Regulatory Review no. NREL/TP-6A20-66998. Washington, D.C: National Renewable Energy Laboratory (NREL)

Meacham, S., Rath, P., Moharana, P. and Phalp, K. (2019) One-stop Shop E-government Solution for South-Korean Government Multiministry Virtual Employment-Welfare Plus Center System. 'The Thirteenth International Conference on Digital Society and eGovernments'. held 24-28 February 2019 at Greece. Wilmington: IARIA

Molfetas, A. and Wille, J. (2018) Leveraging the Technology to Support Construction Regulation and Permitting Reform: Insights from Recent Country Experience. Washington DC: World Bank Group

Pardalis, G., Mainalia, B. and Mahapatraa, K. (2018) One-stop-shop as an innovation, and construction SMEs: A Swedish perspective. 'Proceedings of 10th International Conference on Applied Energy'. held 22-25 August 2018 at Hing Kong. Amsterdam: Elsevier Ltd.

Sina Safinia, Zamarad Al-Hinai, Hussin AM Yahia, Mohammed FM Abushammala, 2017. Sustainable construction in sultanate of Oman: factors effecting materials utilization. Procedia engineering.196. 


\section{Journal of Student Research}

Fourth Middle East College Student Research Conference, Muscat, Sultanate of Oman

Page 980-987

Shahi, K. (2018) Evaluation of Current Construction Permitting Process in City of Toronto and Future of Permitting in the Global Construction Industry. Unpublished dissertation. Toronto: University of Toronto

Smyrichinsky, P. and Kramer, S. (2018) Practical Application Challenges for Construction Submittals in a Paperless Contract File. 'Proceedings of the Creative Construction Conference'. held 30 June - 3 July 2018 at Ljubljana. Budapest: Diamond Congress Ltd. 